\title{
State-dependent Ras signaling and AMPA receptor trafficking
}

\author{
Yi Qin, ${ }^{1,3,5,6}$ Yinghua Zhu, ${ }^{1,5}$ Joel P. Baumgart, ${ }^{1,2,5}$ Ruth L. Stornetta, ${ }^{1}$ Kenneth Seidenman, ${ }^{3}$ \\ Volker Mack, ${ }^{4}$ Linda van Aelst, ${ }^{3}$ and J. Julius $\mathrm{Zhu}^{1,2,7}$ \\ ${ }^{1}$ Department of Pharmacology and ${ }^{2}$ Neuroscience Graduate Program, University of Virginia School of Medicine, \\ Charlottesville, Virginia 22908, USA; ${ }^{3}$ Cold Spring Harbor Laboratory, Cold Spring Harbor, New York 11724, USA; \\ ${ }^{4}$ Department of Molecular Neurobiology, Max Planck Institute for Medical Research, Heidelberg D-69120, Germany
}

Synaptic trafficking of AMPA-Rs, controlled by small GTPase Ras signaling, plays a key role in synaptic plasticity. However, how Ras signals synaptic AMPA-R trafficking is unknown. Here we show that low levels of Ras activity stimulate extracellular signal-regulated kinase kinase (MEK)-p42/44 MAPK (extracellular signal-regulated kinase [ERK]) signaling, whereas high levels of Ras activity stimulate additional Pi3 kinase (Pi3K)-protein kinase $B(P K B)$ signaling, each accounting for $\sim 50 \%$ of the potentiation during long-term potentiation (LTP). Spontaneous neural activity stimulates the Ras-MEK-ERK pathway that drives GluR2L into synapses. In the presence of neuromodulator agonists, neural activity also stimulates the Ras-Pi3K-PKB pathway that drives GluR1 into synapses. Neuromodulator release increases with increases of vigilance. Correspondingly, Ras-MEK-ERK activity in sleeping animals is sufficient to deliver GluR2L into synapses, while additional increased Ras-Pi3K-PKB activity in awake animals delivers GluR1 into synapses. Thus, state-dependent Ras signaling, which specifies downstream MEK-ERK and Pi3K-PKB pathways, differentially control GluR2L- and GluR1-dependent synaptic plasticity.

[Keywords: Ras; Erk; Pi3 kinase; Src; synaptic plasticity; neuromodulators; behavioral states]

Supplemental material is available at http://www.genesdev.org.

Received February 15, 2005; revised version accepted July 5, 2005.

The most widely studied example of synaptic plasticity is long-term potentiation (LTP), the sustained synaptic enhancement after brief periods of repetitive synaptic activity. It is believed that understanding the cellular and molecular mechanisms for LTP will elucidate physiological and pathological phenomena of neural development, adaptation, learning, and memory. In current models of plasticity (Malinow and Malenka 2002; Sheng and Kim 2002; Bredt and Nicoll 2003; Thomas and Huganir 2004), NMDA-sensitive glutamate receptor (-R) opening, a rise in post-synaptic calcium concentration, activation of a variety of kinases, phosphorylation of AMPA-Rs, and synaptic trafficking of AMPA-Rs after synaptic activity are crucial events in synaptic plasticity. However, the biochemical cascades linking NMDA-R activity with activation of kinases and AMPA-R trafficking remain poorly understood.

AMPA-Rs are multimeric proteins composed of the subunits GluR1, GluR2, GluR2L, GluR3, and GluR4

\footnotetext{
${ }^{5}$ These authors contributed equally or significantly to this work. ${ }^{6}$ Present address: Center for Cell Signaling, University of Virginia School of Medicine, Charlottesville, VA 22908, USA.

${ }^{7}$ Corresponding author.

E-MAIL jjzhu@virginia.edu; FAX (434) 982-3878.

Article published online ahead of print. Article and publication date are at http://www.genesdev.org/cgi/doi/10.1101/gad.342205.
}

(Hollmann and Heinemann 1994; Schoepfer et al. 1994; Dingledine et al. 1999). The cytoplasmic C termini of the constituent subunits, which can be either long or short, define the trafficking characteristics of AMPA-Rs (Malinow and Malenka 2002; Sheng and Kim 2002; Bredt and Nicoll 2003; Thomas and Huganir 2004). AMPA-Rs with long cytoplasmic termini (e.g., GluR1- or GluR2L-containing AMPA-Rs) are normally restricted from synapses and driven into synapses during activity-induced synaptic enhancement. Yet, it is not clear why both GluR2L and GluR1 subunits are expressed and required for LTP in juvenile and adult CA1 neurons (Zamanillo et al. 1999; Kolleker et al. 2003). More importantly, whether and how synaptic delivery of GluR2L- and GluR1-containing AMPA-Rs is differentially regulated remains unknown.

Small GTPase Ras, as well as its activators (GEFs) and inactivators (GAPs), are present at synapses, and they control synaptic plasticity and cognitive behaviors (Grewal et al. 1999; Sheng and Kim 2002; Krapivinsky et al. 2003; Tian et al. 2004; Kim et al. 2005). Moreover, diseases causing cognitive impairment are associated with genetic defects of molecules involved in Ras signaling [e.g., H-Ras with autism (Comings et al. 1996), RasGap NF1 with neurofibromatosis (Costa et al. 2002; Tong et al. 2002), Tuberin with tuberous sclerosis (Inoki et al. 2003), 
and Rsk with Coffin-Lowry syndrome and X-linked mental retardation (Trivier et al. 1996; Yntema et al. 1999)]. Furthermore, our recent study showed that low-level Ras activation delivers GluR2L-containing AMPA-Rs into synapses, whereas high-level Ras activation also drives synaptic insertion of GluR1-containing AMPA-Rs (Zhu et al. 2002). Because Ras regulates intracellular processes via multiple pathways, including extracellular signalregulated kinase kinase (MEK)-extracellular signal-regulated kinase (ERK) and phosphoinositide 3-kinase (Pi3K)protein kinase $\mathrm{B}(\mathrm{PKB})$ pathways in nonneuronal cells (White et al. 1995; Rodriguez-Viciana et al. 1997), these findings raise an intriguing possibility that different levels of Ras activity may control GluR2L- and GluR1-mediated LTP via differentially stimulating downstream pathways.

In this study, we tested the hypothesis that levels of Ras activity specify distinct downstream pathways that differentially control GluR2L- and GluR1-mediated synaptic plasticity. We found that spontaneous neural activity, such as that occurring in cultured brain slices or intact brains of sleeping animals, stimulates the RasMEK-ERK pathway sufficiently to induce GluR2L-mediated synaptic potentiation. In contrast, in intact brains of awake animals where neuromodulator release is generally increased (Steriade and McCarley 1990), neural activity additionally stimulates the Ras-Pi3K-PKB pathway, which, together with Ras-MEK-ERK activity, is required to induce GluR1-mediated synaptic potentiation. Notably, Ras activity coordinates multiple downstream signaling pathways (i.e., Ras-MEK-ERK and Ras-Pi3KPKB pathways) that control neoplastic proliferation and transformation as well as GluR2L- and GluR1-mediated synaptic plasticity.

\section{Results}

Active Ras mutants enhance AMPA-R-mediated synaptic transmission

To test whether Ras signals synaptic potentiation via multiple pathways, we generated three GFP-tagged Ras mutant constructs from a constitutively active Ras(V12) background: T35 $\rightarrow$ S [Ras(S35)-GFP], E37 $\rightarrow$ G [Ras(G37)-GFP], and Y40 $\rightarrow$ C [Ras(C40)-GFP]. These three active Ras mutants are known to specifically activate distinct Ras effectors: C-Raf (also known as Raf-1), B-Raf and/or RalGEF, and Pi3K, respectively (White et al. 1995; Yamamori et al. 1995; Rodriguez-Viciana et al. 1997). Dependent on cell type, Ras(S35) and/or Ras(G37) can stimulate ERK activity, which may be mediated by C-Raf and/or B-Raf (Moodie et al. 1994; White et al. 1995; Yamamori et al. 1995; Rodriguez-Viciana et al. 1997). In addition, Ras(G37) can also stimulate Ral activity (Rodriguez-Viciana et al. 1997). On the other hand, Ras(C40) activates Pi3K, which can subsequently stimulate PKB (also known as Akt) activity (Bos 1995; Datta et al. 1999). These GFP-tagged active Ras constructs, when expressed, produced strong GFP fluorescence, which allowed unambiguous identification of expressing cells.
Two photon images of CAl pyramidal neurons expressing these Ras mutants revealed a homogeneous expression pattern, including expression in dendritic spines (Fig. 1A), sites for excitatory synaptic contacts. These results indicate that Ras mutants can travel to synapses.

To determine whether these Ras mutants affect synaptic transmission, electrophysiological recordings were obtained simultaneously from nearby expressing and nonexpressing CA1 neurons. Afferent fibers were stimulated and excitatory post-synaptic currents were recorded. Neurons expressing Ras(G37)-GFP or Ras(C40)GFP had enhanced AMPA-R-mediated synaptic responses compared with nearby nonexpressing cells, whereas neurons expressing Ras(S35)-GFP had the same AMPA responses compared with nearby nonexpressing cells (Fig. 1B-E). NMDA-R-mediated responses were not different between expressing and nearby nonexpressing neurons (Fig. 1B-E). These results are consistent with the finding that synaptic NMDA-Rs and AMPA-Rs are differentially regulated (Rao and Craig 1997), and suggest that Ras(G37)-GFP- or Ras(C40)-GFP-mediated potentiations were mediated by post-synaptic, but not presynaptic mechanisms.

To determine which downstream Ras signaling pathways mediate the Ras(G37)-GFP- or Ras(C40)-GFP-mediated synaptic potentiation in CA1 neurons, we included PD98059, which inhibits MEK, the ERK activating enzyme (Dudley et al. 1995), and LY294002, which inhibits Pi3K (Davies et al. 2000), during expression of Ras(G37)GFP and Ras(C40)-GFP. We found that the Ras(G37)GFP-stimulated potentiation was blocked by PD98059, whereas Ras(C40)-GFP-stimulated potentiation was blocked by LY294002 (Fig. 1D,E). These results suggest that in CA1 neurons, Ras(G37) mutant, but not Ras(S35) mutant, potentiates AMPA responses via stimulating ERK activity, while Ras(C40) mutant does so via promoting Pi3K activity. Interestingly, Ras(C40)-GFP-stimulated potentiation was also blocked by PD98059 (Fig. 1E), suggesting that the potentiation may require spontaneous ERK activity (Zhu et al. 2002).

To confirm that the Ras(G37) mutant stimulates ERK activity and the Ras $(\mathrm{C} 40)$ mutant activates Pi3K in CA1 neurons, we examined the phosphorylated (active) form of ERK and PKB in CA1 cells expressing these active Ras mutants. Western blot analysis indicates that the phosphorylated ERK was selectively enhanced in tissues expressing Ras(G37)-GFP, while the phosphorylated PKB was selectively enhanced in tissues expressing Ras(C40)GFP (Fig. 2A,B). Expressing Ras(S35)-GFP had no effect on phosphorylation of ERK and PKB. Lack of ERK activation with this mutant was somewhat surprising. We wanted to ensure that this mutant was functional and to this end we infected HeLa cells with Ras(S35)-GFP virally. HeLa cells expressing Ras(S35)-GFP had a significantly higher level of the phosphorylated form of ERK (Supplementary Fig. S1), consistent with our previous report (White et al. 1995). Previous studies have shown that Ras(G37) can stimulate B-Raf, as well as Ral (White et al. 1995; Yamamori et al. 1995; Rodriguez-Viciana et al. 1997). We found that expressing Ras(G37)-GFP in- 
Figure 1. Expression and functional effects of active Ras mutants in hippocampal neurons. (A) Two-photon images of GFP fluorescence indicate that Ras(S35)-GFP, Ras(G37)-GFP, and Ras(C40)-GFP proteins are present in the dendrites and spines of CAl pyramidal neurons. The dendritic spines are illuminated by RFP fluorescence. $(B)$ Evoked AMPA-R-mediated $(-60 \mathrm{mV})$ and NMDA-R-mediated $(+40 \mathrm{mV})$ responses recorded from nonexpressing (Ctrl) and Ras(S35)-GFP-, Ras(G37)GFP-, or Ras(C40)-GFP-expressing cells. These active Ras mutants were expressed in cultured slices in normal culture media for $\sim 15 \mathrm{~h}$. (C, top) AMPA responses in Ras(S35)-GFP-expressing cells cultured in normal media $(n=14, p=0.68)$. (Bottom) NMDA responses in Ras(S35)-GFP-expressing cells cultured in normal media $(n=14, p=0.38)$. ( $D$, top $)$ AMPA responses in Ras(G37)-GFP-expressing cells cultured in normal media $(n=14, p<0.01)$, or in media with $10 \mu$ L LY294002 (LY) $(n=14, p<0.01)$ or with $25 \mu \mathrm{M}$ PD98059 (PD) $(n=14, p=0.76)$. (Bottom) NMDA responses in Ras(G37)-GFP-expressing cells cultured in normal media $(n=14, p=0.51)$, or in media with $10 \mu$ L LY294002 $(n=14, p=0.75)$ or with $25 \mu \mathrm{M}$ PD98059 $(n=14$, $p=0.68)$. (E, top) AMPA responses in Ras(C40)-GFP-expressing cells cultured in normal media $(n=14$, $p<0.01)$, or in media with $10 \mu \mathrm{M}$ LY294002 $(n=16$,

A Ras(S35)-GFP + RFP
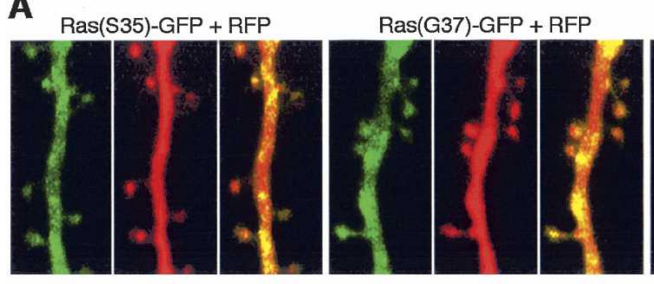

Ras(C40)-GFP + RFP
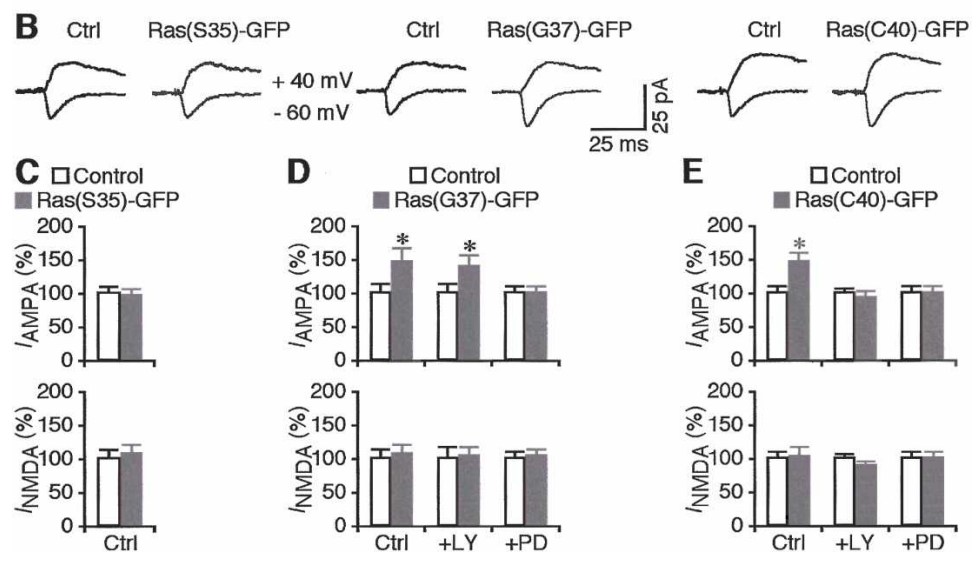

$p=0.45$ ) or with $25 \mu \mathrm{M}$ PD98059 ( $n=14, p=0.98)$. (Bottom) NMDA responses in Ras(C40)-GFP-expressing cells cultured in normal media $(n=14, p=0.43)$, or in media with $10 \mu \mathrm{M}$ LY294002 $(n=16, p=0.08)$ or with $25 \mu \mathrm{M}$ PD98059 $(n=14, p=0.93)$. AMPA-R- and NMDA-R-mediated current amplitude and standard errors were normalized to average values from control cells. Asterisk indicates $p<0.05$ (Wilcoxon test).

creased the phosphorylated B-Raf, but had no effect on the levels of phosphorylated C-Raf and active GTPbound Ral in CA1 cells (Supplementary Fig. S2). These results suggest that Ras(G37) stimulates ERK activity via B-Raf in CA1 cells. Together these results suggest that Ras mutants engage different downstream effectors depending on cell type, consistent with previous findings (White et al. 1995; Yamamori et al. 1995; Rodriguez-Viciana et al. 1997). Collectively, the results indicate that stimulation of Ras-MEK-ERK or Ras-Pi3K-PKB pathway selectively up-regulates AMPA-R-mediated synaptic responses.

\section{Ras pathways control phosphorylation and synaptic insertion of GluR2L and GluR1}

We showed previously that neurons expressing GluR2L(R $\rightarrow$ Q)-GFP have enhanced AMPA responses and rectification compared with nearby nonexpressing neurons (Kolleker et al. 2003). In this construct, an $\mathrm{R} \rightarrow \mathrm{Q}$ mutation is generated at its pore region to make it a rectified channel, or electrophysiologically "tagged" (Kolleker et al. 2003). Because AMPA-R-mediated responses in pyramidal neurons are largely nonrectifying (Hestrin et al. 1990), synaptic insertion of GluR2L(R $\rightarrow$ Q)-GFP will be indicated by the enhancement of amplitude and rectification of AMPA responses. We previously reported that synaptic insertion of GluR2L/R $\rightarrow$ Q)-GFP requires Ras signaling since blocking Ras activity blocks the enhanced rectification and amplitude of
AMPA responses in GluR2L( $\rightarrow$ Q)-GFP-expressing neurons (Zhu et al. 2002). In this study, we found that PD98059, but not LY294002, blocked enhanced transmission and rectification in GluR2L(R $\rightarrow$ Q)-GFP-expressing neurons (Fig. 3A,B). These results indicate that GluR2L-mediated potentiation requires Ras-MEK-ERK signaling. Moreover, neurons coexpressing GluR2L $/ \mathrm{R} \rightarrow$ Q)-GFP with Ras(G37)-GFP had enhanced AMPA responses and rectification compared with nonexpressing neurons (Fig. 3A,B). The amounts of increase in AMPA responses and rectification in these neurons are the same as neurons expressing GluR2L(R $\rightarrow$ Q)-GFP alone. As a control, we found that neurons coexpressing GluR2L/R $\rightarrow$ Q)-GFP with Ras(C40)-GFP had increased AMPA responses that equal approximately the sum of neurons expressing GluR2L(R $\rightarrow$ Q)-GFP and Ras(C40)-GFP alone (Fig. 3B). These results indicate that Ras(G37)-GFP-mediated, but not Ras(C40)-GFP-mediated, potentiation occludes GluR2L(R $\rightarrow$ Q)-GFP-mediated potentiation. Together, these results indicate that Ras-MEK-ERK activity is necessary and sufficient to drive synaptic insertion of GluR2L(R $\rightarrow$ Q)-GFP.

But how does activation of Ras-MEK-ERK deliver GluR2L into synapses? Previous studies suggested that phosphorylation of AMPA-Rs with long cytoplasmic termini leads to their synaptic insertion (Song and Huganir 2002). S841 at cytoplasmic termini of GluR2L, which corresponds to S845 in GluR1 and S842 in GluR4, seems a likely phosphorylation site critical for synaptic delivery of GluR2L. Thus, we made the point mutation 
A

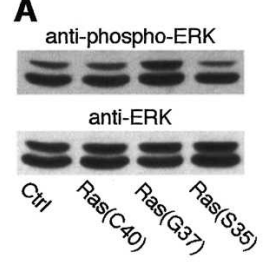

B
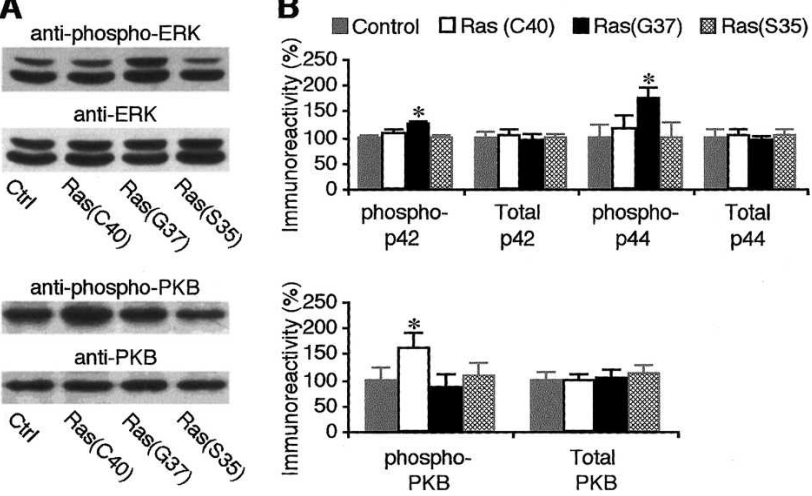

Figure 2. Ras mutants selectively stimulate MEK-ERK and Pi3K-PKB pathways. (A) Western blots of phospho-ERK or phospho-PKB in control hippocampal CA1 region, and hippocampal CA1 region expressing Ras(C40)-GFP, Ras (G37)-GFP, and Ras(S35)-GFP. Each lane was loaded with the same amount of protein $(40 \mu \mathrm{g})$. (B, top) Relative amounts of phospho-ERK (i.e., p42 and p44 bands) in hippocampal CA1 region expressing $\operatorname{Ras}(\mathrm{C} 40)-\mathrm{GFP}(n=10, p=0.33$ for phospho-p42; $n=10, p=0.26$ for phospho-p44), Ras(G37)-GFP $(n=10, p<0.01$ for phosphop42; $n=10, p<0.01$ for phospho-p44), or Ras(S35)-GFP ( $n=10$, $p=0.88$ for phospho-p42; $n=10, p=0.65$ for phospho-p44). Relative amounts of total ERK (i.e., p42 and p44 bands) in hippocampal CA1 region expressing Ras(C40)-GFP $(n=10, p=0.20$ for $\mathrm{p} 42 ; n=10, p=0.72$ for $\mathrm{p} 44)$, Ras(G37)-GFP $(n=10, p=0.72$ for $\mathrm{p} 42 ; n=10, p=0.80$ for $\mathrm{p} 44)$, or $\operatorname{Ras}(\mathrm{S} 35)$-GFP $(n=10$, $p=0.80$ for $\mathrm{p} 42 ; n=10, p=0.80$ for $\mathrm{p} 44)$. (Bottom) Relative amounts of phospho-PKB in hippocampal CA1 region expressing $\operatorname{Ras}(\mathrm{C} 40)-\mathrm{GFP}(n=10, p<0.05), \operatorname{Ras}(\mathrm{G} 37)-\mathrm{GFP} \quad(n=10$, $p=0.77)$, or Ras(S35)-GFP $(n=10, p=0.72)$. Relative amounts of total PKB in hippocampal CA1 region expressing Ras(C40)-GFP $(n=10, p=0.65)$, Ras(G37)-GFP $(n=10, p=0.72)$, or Ras(S35)GFP $(n=10, p=0.31)$. The relative values and standard errors were normalized to average amounts of phospho-ERK and phospho-PKB or total ERK and total PKB from the control hippocampal CA1 region. Asterisk indicates $p<0.05$ (Wilcoxon test).

S841 $\rightarrow$ D at GluR2L(R $\rightarrow$ Q)-GFP, GluR2L(841D)-GFP, to mimic phosphorylation and found that neurons expressing GluR2L(841D)-GFP had increased synaptic responses and rectification even if PD98059 was included in the culture media (Fig. 3B). This result suggests that Ras-MEK-ERK signaling drives GluR2L into synapses via phosphorylation of its S841.

Neither spontaneous synaptic activity nor spontaneous Ras activity in culture slices is enough to drive synaptic delivery of GluR1 (Shi et al. 2001; Zhu et al. 2002). On the other hand, strong Ras activity drives GluR1 into synapses because neurons cotransfected with Ras(ca)GFP and GluR1-GFP, which is also "electrophysiologically tagged" (Hayashi et al. 2000), exhibit increased AMPA responses and rectification (Zhu et al. 2002). We wished to know whether the strong Ras signaling-stimulated synaptic insertion of GluR1-GFP requires activation of MEK-ERK and/or Pi3K-PKB signaling pathways. We found that either PD98059 or LY294002 blocked the increased rectification in neurons coexpressing Ras(ca)-GFP and GluR1-GFP (Fig. 4A,B). Moreover, neurons coexpressing Ras(G37)-GFP with Ras(C40)-GFP and
GluR1-GFP had the same increased synaptic responses and rectification as neurons coexpressing Ras(ca)-GFP with GluR1-GFP (Fig. 4A,B; see also Zhu et al. 2002). Furthermore, neurons coexpressing Ras(G37)-GFP and GluR1-GFP had increased synaptic responses, yet the rectification was the same compared with nearby nonexpressing neurons (Fig. 4A,B), indicating no synaptic delivery of GluR1-GFP. Finally, neurons expressing Ras(C40)-GFP with GluR1-GFP had increased synaptic responses and enhanced rectification (Fig. 4A,B), indicating synaptic delivery of GluR1-GFP. These results indicate that strong Ras activity, which stimulates both RasMEK-ERK and Ras-Pi3K-PKB pathways, is required for GluR1-dependent synaptic potentiation.

Phosphorylation of S831 and S845 at GluR1 cytoplasmic termini is crucial for GluR1-mediated synaptic potentiation (Lee et al. 2000). To determine whether RasMEK-ERK and Ras-Pi3K-PKB pathways control phosphorylation of these sites, we made single and double point mutations $\mathrm{S} 831 \rightarrow \mathrm{D}$ and/or S845 $\rightarrow \mathrm{D}$ at GluR1 cytoplasmic termini to mimic the phosphorylation at

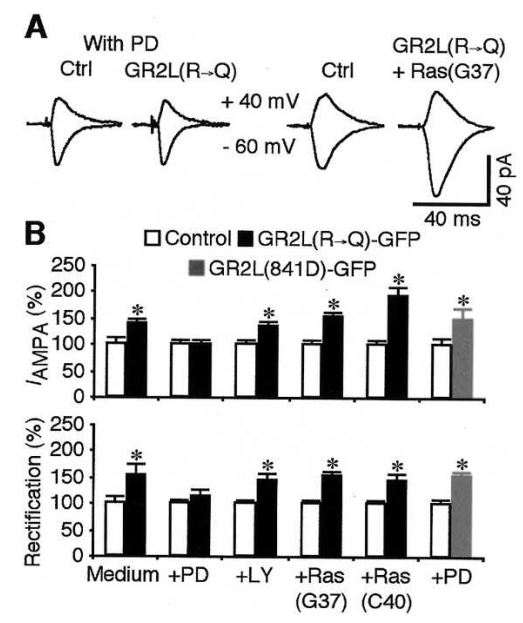

Figure 3. Ras-MEK-ERK signaling drives synaptic insertion of GluR2L. (A) Evoked AMPA-R-mediated responses recorded from nonexpressing cells (Ctrl) and cells expressing GluR2L(R $\rightarrow$ Q)-GFP or coexpressing GluR2L(R $\rightarrow$ Q)-GFP with Ras(G37)-GFP. (B, top) AMPA responses in GluR2L(R $\rightarrow$ Q)GFP-expressing cells cultured in normal media $(n=16$, $p<0.05)$, or in media containing $25 \mu \mathrm{M}$ PD98059 $(n=14$, $p=0.93)$ or $10 \mu \mathrm{M}$ LY294002 $(n=14, p<0.005)$; and cells coexpressing GluR2L(R $\rightarrow$ Q)-GFP with Ras(G37)-GFP (n=16, $p<0.001)$ or with Ras(C40)-GFP $(n=16, p<0.001)$; and GluR2L(841D)-GFP-expressing cells cultured in media containing $25 \mu \mathrm{M}$ PD98059 ( $n=14, p<0.005)$. (Bottom) Rectification of GluR2L(R $\rightarrow$ Q)-GFP-expressing cells cultured in normal media (ctrl, $1.91 \pm 0.24 ; \exp , 2.90 \pm 0.44 ; n=16, p<0.005$ ); in media containing $25 \mu \mathrm{M}$ PD98059 $(n=14, p=0.25)$ or $10 \mu \mathrm{M}$ LY294002 $(n=14, p<0.005)$; and cells coexpressing GluR2L(R $\rightarrow$ Q)-GFP with Ras(G37)-GFP ( $n=16, p<0.001)$ or with Ras(C40)-GFP $(n=16, p<0.001)$; and GluR2L(841D)-GFPexpressing cells cultured in media containing 25 HM PD98059 $(n=14, p<0.005)$. AMPA-R-mediated current amplitude, rectification, and standard errors were normalized to average values from control cells. Asterisk indicates $p<0.05$ (Wilcoxon test). 
Figure 4. Ras-MEK-ERK and Ras-Pi3K-PKB signaling drives synaptic insertion of GluR1. (A) Evoked AMPA-R-mediated responses recorded from nonexpressing cells (Ctrl) and cells coexpressing GluR1-GFP with Ras(ca)GFP. $(B$, top) AMPA responses in GluR1-GFP and Ras(ca)-GFP-coexpressing cells cultured in media containing $25 \mu M$ PD98059 $(n=16$, $p=0.87$ ); GluR1-GFP and Ras(ca)-GFP-coexpressing cells cultured in media containing 10 $\mu$ L LY294002 ( $n=14, p<0.05)$; GluR1-GFP, Ras(G37)-GFP, and Ras(C40)-GFP-coexpressing cells $(n=14, p<0.005)$; GluR1-GFP and Ras(G37)-GFP-coexpressing cells $(n=14$, $p<0.05)$; and GluR1-GFP and Ras(C40)-GFPcoexpressing cells $(n=14, p<0.01)$. (Bottom) Bectification of GluR1-GFP and Ras(ca)-GFPcoexpressing cells cultured in media containing $25 \mu \mathrm{M}$ PD98059 $(n=16, p=0.96)$; GluR1GFP and Ras(ca)-GFP-coexpressing cells cultured in media containing $10 \mu \mathrm{M}$ LY294002 ( $n=14, p=0.88)$; GluR1-GFP, Ras(G37)-GFP, and Ras(C40)-GFP-coexpressing cells $(n=14$, $p<0.01$ ); GluR1-GFP and Ras(G37)-GFP coexpressing cells $(n=14, p=0.31)$; and GluR1GFP and Ras(C40)-GFP-coexpressing cells $(n=14, p<0.05) .(C)$ Evoked AMPA-R-mediated responses recorded from nonexpressing cells (Ctrl) and cells expressing GluR1(DD)GFP, expressing GluR1(831D)-GFP, or coexpressing GluR1(831D)-GFP with Ras(G37)GFP. $(D$, left $)$ AMPA responses in cells expressing GluR1(DD)-GFP maintained in normal media $(n=16, p<0.01)$, or media containing $12 \mathrm{mM} \mathrm{Mg}^{2+}(n=16, p<0.05)$ or $10 \mu \mathrm{M}$

A
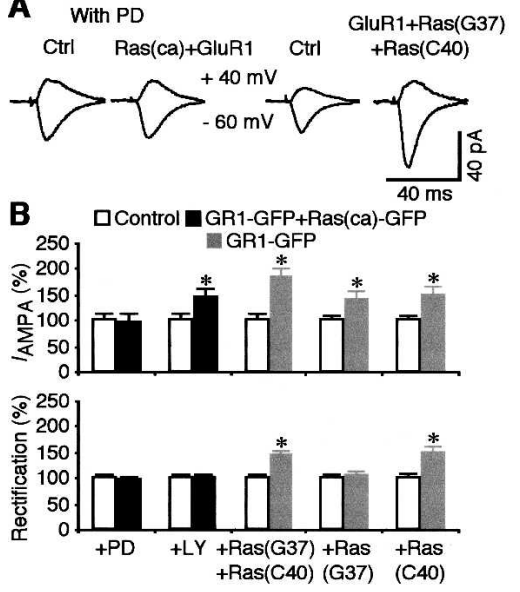

C

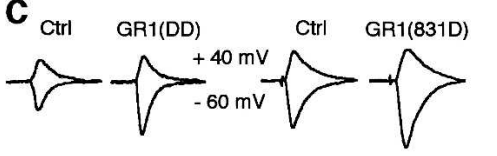

With PD
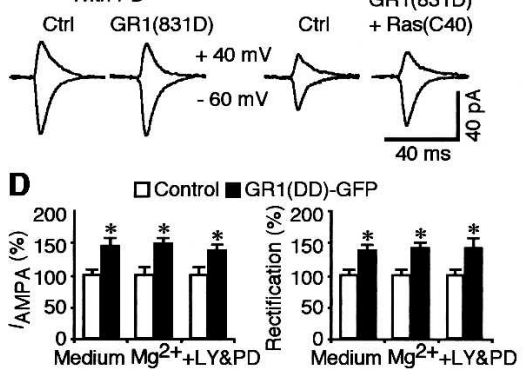

E
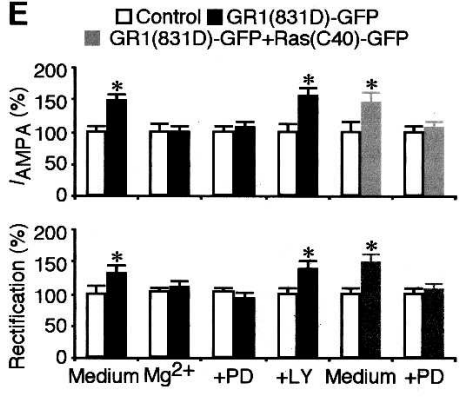

F With PD
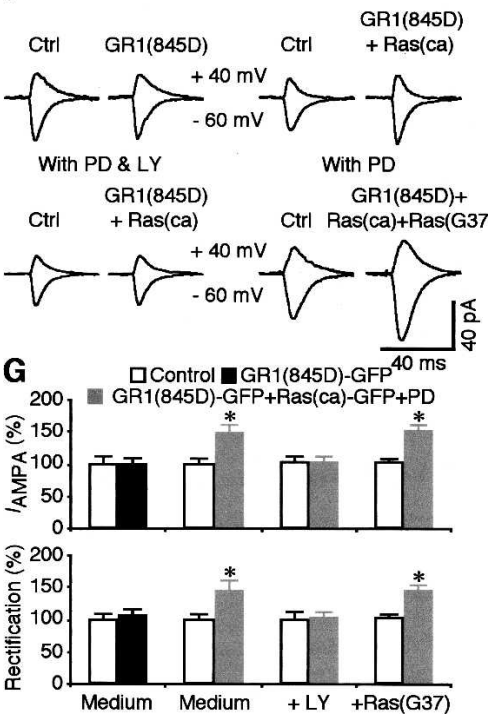

LY294002 and $25 \mu$ M PD98059 ( $n=14, p<0.05)$. (Right) Rectification of cells expressing GluR1(DD)-GFP maintained in normal media $(n=16, p<0.005)$, or media containing $12 \mathrm{mM} \mathrm{Mg}^{2+}(n=16, p<0.01)$ or $10 \mu \mathrm{M}$ LY294002 and $25 \mu \mathrm{M}$ P $98059(n=14, p<0.05)$. (E, top) AMPA responses for GluR1(831D)-GFP-expressing slices maintained in normal media $(n=16, p<0.01)$, or media containing 12 $\mathrm{mM} \mathrm{Mg}^{2+}(n=16, p=0.88), 25 \mu \mathrm{M}$ PD98059 ( $\left.n=16, p=0.57\right)$, or $10 \mu \mathrm{M}$ LY294002 ( $\left.n=12, p<0.05\right)$, and for GluR1(831D)-GFP and Ras(C40)-GFP-coexpressing cells maintained in normal media $(n=16, p<0.01)$ or media containing $25 \mu M$ PD98059 ( $n=14, p=0.68)$. (Bottom) Rectification for GluR1(831D)-GFP-expressing slices maintained in normal media $(n=16, p<0.005)$, or media containing 12 $\mathrm{mM} \mathrm{Mg}^{2+}(n=16, p=0.68), 25 \mu \mathrm{M}$ PD98059 ( $\left.n=16, p=0.72\right)$, or $10 \mu \mathrm{M}$ LY294002 $(n=12, p<0.01)$, and for GluR1(831D)-GFP and Ras(C40)-GFP-coexpressing cells maintained in normal media $(n=14, p<0.005)$ or media containing $25 \mu M$ PD98059 ( $n=14$, $p=0.47)$. $(F)$ Evoked AMPA-R-mediated responses recorded from nonexpressing cells (Ctrl) and cells expressing GluR1(845D)-GFP, coexpressing GluR1(845D)-GFP with Ras(ca)-GFP, or coexpressing GluR1(845D)-GFP with Ras(ca)-GFP and Ras(C40)-GFP. (G, top) AMPA responses for GluR1(845D)-GFP-expressing slices maintained in normal media $(n=18, p=0.97)$; for GluR1(845D)-GFP with Ras(ca)-GFP-coexpressing slices maintained in media containing $25 \mu$ M PD98059 ( $n=14, p<0.01$ ) or with additional $10 \mu M$ LY294002 $(n=14, p<0.88)$; and for GluR1(845D)-GFP, Ras(ca)-GFP, and Ras(G37)-GFP-coexpressing slices maintained in media containing 25 $\mu M$ PD98059 ( $n=14, p<0.005)$. (Bottom) Rectification for GluR1(845D)-GFP-expressing slices maintained in normal media $(n=18$, $p=0.85)$; for GluR1(845D)-GFP with Ras(ca)-GFP-coexpressing slices maintained in media containing $25 \mu M$ PD98059 ( $n=14$, $p<0.005)$ or with additional $10 \mu \mathrm{M}$ LY294002 ( $n=14, p=0.98)$; and for GluR1(845D)-GFP, Ras(ca)-GFP, and Ras(G37)-GFP-coexpressing slices maintained in media containing $25 \mu \mathrm{M}$ PD98059 $(n=14, p<0.01)$. AMPA-R-mediated current amplitude, rectification, and standard errors were normalized to average values from control cells. Asterisk indicates $p<0.05$ (Wilcoxon test).

these residues. Neurons expressing GluR1 with double phosphorylation site mutations, GluR1(DD)-GFP, had increased AMPA responses and rectification compared with nearby nonexpressing neurons, and these effects were not blocked by high $\mathrm{Mg}^{2+}$, which suppresses synaptic activity (Zhu et al. 2000), nor by PD98059 and LY294002 (Fig. 4C,D). These results suggest that Ras signaling is not required for synaptic insertion of GluR1(DD)-GFP.

We then examined neurons expressing GluR1 with a single phosphorylation site mutation. Neurons expressing GluR1 with the S831 $\rightarrow$ D mutation, GluR1(831D)GFP, had increased AMPA responses and rectification, and these effects were blocked by high $\mathrm{Mg}^{2+}$ or PD98059, but not by LY294002 (Fig. 4C,E). Moreover, neurons coexpressing GluR1(831D)-GFP with Ras(C40)-GFP had the same enhanced AMPA responses and rectification (Fig. 4C,E), indicating the same amount synaptic delivery of GluR1(831D)-GFP. The enhanced AMPA responses and rectification in neurons coexpressing 
GluR1(831D)-GFP with Ras(C40)-GFP were blocked by PD98059 (Fig. 4E), consistent with the notion that synaptic delivery of GluR1 requires spontaneous ERK activity. These results indicate that (spontaneous) Ras-MEKERK signaling is required and sufficient for synaptic insertion of GluR1(831D)-GFP.

Finally, we examined neurons expressing GluR1 with the S845 $\rightarrow$ D mutation, GluR1(845D)-GFP. Neurons expressing GluR1(845D)-GFP had no change in AMPA responses and rectification (Fig. 4F,G), whereas neurons coexpressing GluR1(845D)-GFP with Ras(ca)-GFP had increased AMPA responses and rectification even when PD98059 was included in the culture media. Including additional LY294002 blocked the increased AMPA responses and rectification in neurons coexpressing GluR1(845D)-GFP with Ras(ca)-GFP (Fig. 4F,G). Moreover, neurons coexpressing GluR1(845D)-GFP with
Ras(ca)-GFP and Ras(G37)-GFP had the same enhanced AMPA responses and rectification as neurons coexpressing GluR1(845D)-GFP with Ras(ca)-GFP (Fig. 4F,G). These results indicate that additional Ras-Pi3K-PKB signaling is required for synaptic insertion of GluR1(845D)GFP (cf. Passafaro et al. 2001). Together, these results suggest that Ras-MEK-ERK and Ras-Pi3K-PKB pathways control synaptic insertion of GluR1 by triggering phosphorylation of S845 and S831 of GluR1, respectively.

To determine whether activation of Ras-MEK-ERK drives synaptic insertion of endogenous GluR2L and additional activation of Ras-Pi3K-PKB also drives synaptic insertion of endogenous GluR1, we examined the effects of Ras signaling in GluR1 and GluR2 knockout mice (Fig. 5A-C). Previous studies suggested that synaptic trafficking of GluR2L is normal in GluR1 knockout mice
A

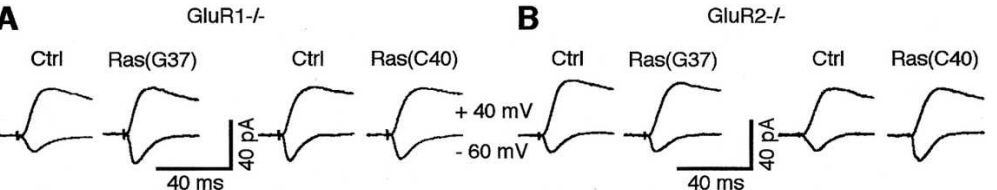

C
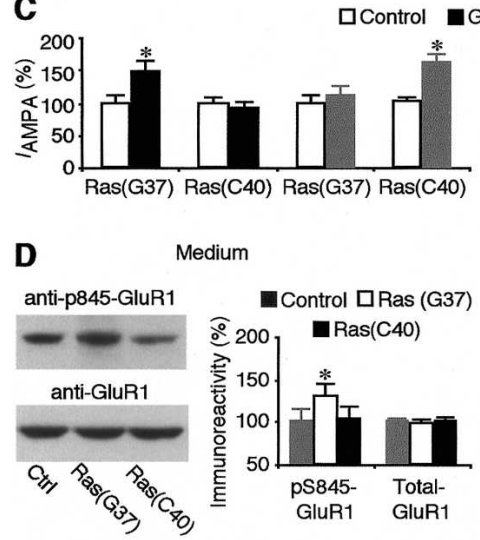

F With PB98059

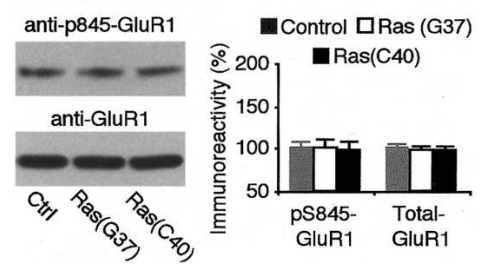

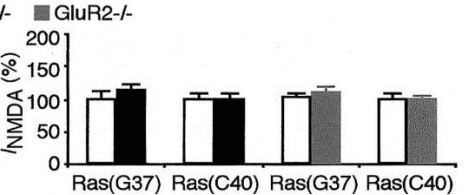

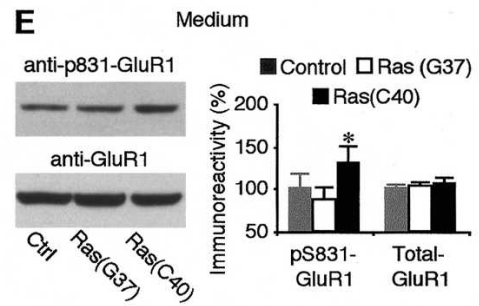

G With LY294002

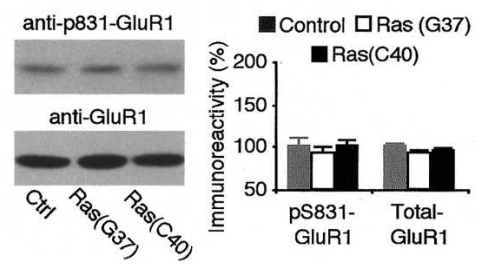

Figure 5. Ras pathways control phosphorylation and synaptic insertion of GluR2L and GluR1. $(A, B)$ Evoked AMPA-R- and NMDA-R-mediated responses recorded from nonexpressing (Ctrl) and Ras(G37)-GFP- or Ras(C40)-GFP-expressing CA1 neurons from GluR1 $(A)$ and GluR2 $(B)$ knockout mice. These active Ras mutants were expressed in cultured slices in normal culture media for $\sim 15 \mathrm{~h}$. (C, left) AMPA responses in GluR1 $1^{-/}[n=14$, $p<0.005$ for Ras (G37)-GFP; $n=14, p=0.53$ for Ras (C40)-GFP $]$ and GluR2 ${ }^{--}[n=14, p=0.30$ for Ras (G37)-GFP; $n=14, p<0.005$ for Ras (C40)-GFP] cells expressing active Ras mutants. (Right) NMDA responses in GluR1 ${ }^{-/-}[n=14, p=0.25$ for Ras (G37)GFP; $n=14, p=0.65$ for Ras (C40)-GFP] and GluR2 $^{-/-}[n=14, p=0.16$ for Ras (G37)-GFP; $n=14$, $p=0.87$ for Ras (C40)-GFP] cells expressing active Ras mutants. AMPA-R- and NMDA-R-mediated current amplitude and standard errors were normalized to average values from control cells. $(D$, left $)$ Western blots of phospho-p845-GluR1 in control hippocampal CA1 region, hippocampal CA1 region expressing Ras (G37)-GFP, and Ras(C40)-GFP cultured in normal media. (Right) Relative amounts of phospho-p845-GluR1 in hippocampal CA1 region expressing Ras(G37)-GFP $(n=15, \quad p<0.05)$ or Ras(C40)-GFP $(n=15, p=0.65)$. Relative amounts of total GluR1 in hippocampal CA1 region expressing Ras(G37)-GFP $(n=15, p=0.57)$ or Ras(C40)-GFP $(n=15, p=0.55)$. $(E$, left $)$ Western blots of phosphop831-GluR1 in control hippocampal CA1 region, hippocampal CA1 region expressing Ras (G37)-GFP, and Ras(C40)-GFP cultured in normal media. (Right) Relative amounts of phospho-p831-GluR1 in hippocampal CA1 region expressing Ras(G37)-GFP $(n=12, p=0.35)$ or Ras(C40)-GFP $(n=12, p<0.01)$. Relative amounts of total GluR1 in hippocampal CA1 region expressing Ras(G37)-GFP $(n=12, p=0.48)$ or Ras(C40)-GFP $(n=12, p=0.16)$. (F, left) Western blots of phospho-p845-GluR1 in control hippocampal CA1 region, hippocampal CA1 region expressing Ras (G37)-GFP, and Ras(C40)-GFP cultured in media containing $25 \mu \mathrm{M}$ PD98059. (Right) Relative amounts of phospho-p845-GluR1 in hippocampal CA1 region expressing Ras(G37)-GFP ( $n=14, p=0.68)$ or Ras(C40)-GFP $(n=14, p=0.47)$. Relative amounts of total GluR1 in hippocampal CA1 region expressing Ras(G37)-GFP $(n=14$, $p=0.46)$ or Ras(C40)-GFP $(n=14, p=0.55)$. (G, left) Western blots of phospho-p831-GluR1 in control hippocampal CA1 region, hippocampal CA1 region expressing Ras (G37)-GFP, and Ras(C40)-GFP cultured in media containing $10 \mu M$ LY294002. (Right) Relative amounts of phospho-p831-GluR1 in hippocampal CA1 region expressing Ras(G37)-GFP $(n=14, p=0.51)$ or Ras(C40)-GFP $(n=14$, $p=0.71)$. Relative amounts of total GluR1 in hippocampal CA1 region expressing Ras(G37)-GFP $(n=14, p=0.08)$ or Ras(C40)-GFP $(n=14, p=0.09)$. Each lane was loaded with the same amount of protein $(40 \mu \mathrm{g})$. The relative values and standard errors were normalized to average amounts of phospho-p831-GluR1 and phospho-p845-GluR1 or total GluR1 from control hippocampal CA1 region. Asterisk indicates $p<0.05$ (Wilcoxon test). 
and that synaptic trafficking of GluR1 is normal in GluR2 knockout mice (Shi et al. 2001; Kolleker et al. 2003). We found that expressing Ras(G37)-GFP enhanced AMPA responses in GluR1 knockout neurons, whereas expressing Ras(C40)-GFP did not. Additionally, expressing Ras (C40)-GFP enhanced AMPA responses in GluR2 knockout neurons, but expressing Ras(G37)-GFP did not. These results indicate that Ras(C40)-GFP-induced potentiation is mediated by GluR1 whereas Ras(G37)-GFP-induced potentiation is mediated by GluR2L.

Consistent with these results, Western blot analysis in rat tissues showed that expressing Ras(G37)-GFP selectively increased phosphorylation of $\mathrm{S} 845$ of GluR1, whereas expressing Ras(C40)-GFP selectively increased phosphorylation of S831 of GluR1 (Fig. 5D,E). As controls, we found that MEK inhibitor PD98059 and Pi3K inhibitor LY294002 blocked the Ras(G37)-GFP- and Ras(C40)-GFP-stimulated phosphorylation of S845 and S831 of GluR1, respectively (Fig. 5F,G). Collectively, these results indicate that Ras-MEK-ERK and RasPi3K-PKB pathways control synaptic delivery of GluR2L and GluR1 by targeting different phosphorylation sites.

\section{Ras pathways control GluR2L- and GluR1-mediated LTP}

We showed previously that Ras activity is necessary and sufficient for LTP (Zhu et al. 2002). To further assess the contribution of the specific Ras signaling through MEKERK and Pi3K-PKB pathways to synaptic potentiation, we examined LTP in neurons expressing Ras(G37)-GFP or Ras(C40)-GFP. Synaptic responses of neurons expressing Ras(G37)-GFP were initially 40\% larger compared with nearby nonexpressing neurons. Pairing stimuli produced LTP in the paired pathway of both Ras(G37)-GFPexpressing and nearby nonexpressing neurons, but neurons expressing Ras(G37)-GFP had smaller LTP, 50\% of that in nearby nonexpressing neurons (Fig. 6A,B). These results indicate that activation of the Ras-MEK-ERK pathway occludes $\sim 50 \%$ of LTP. Similarly, neurons expressing Ras(C40)-GFP had enhanced AMPA responses compared with nearby nonexpressing neurons. Moreover, Ras(C40)-GFP-expressing neurons had $\sim 50 \%$ of LTP as nearby nonexpressing neurons (Fig. 6C,D). Together, these results indicate that activation of the RasMEK-ERK and Ras-Pi3K-PKB pathway each occludes $\sim 50 \%$ of LTP. Consistent with this view, neurons coexpressing Ras(G37)-GFP with Ras(C40)-GFP initially had enhanced synaptic responses ( $80 \%$ larger compared with nonexpressing neurons), but no LTP (Fig. 6E,F). We also examined the role of endogenous Ras-MEK-ERK and Ras-Pi3K-PKB signaling in LTP (Fig. 6E,F). In the presence of LY294002, CA1 neurons had reduced ( 50\% of the normal) LTP, indicating that Pi3K signaling is required for $\sim 50 \%$ LTP (cf. Sanna et al. 2002; Man et al. 2003; Opazo et al. 2003). We reported previously that PD98059 blocks all LTP (Zhu et al. 2002), which is consistent with our above findings that both GluR2L- and GluR1-dependent potentiations require Ras-MEK-ERK activity. Thus, we examined LTP in neurons expressing
GluR1(845D)-GFP, whose synaptic insertion does not require Ras-MEK-ERK activity. We found that in the presence of PD98059, GluR1(845D)-GFP-expressing neurons had reduced $(-50 \%$ of normal) LTP (Fig. $6 \mathrm{E}, \mathrm{F})$, confirming the requirement of spontaneous ERK for GluR2Land GluR1-mediated potentiation. Taken together, these results indicate that Ras-MEK-ERK activity is necessary for LTP but only sufficient for 50\% of LTP (mediated by GluR2L), and additional Ras-Pi3K-PKB activity is required for the other $50 \%$ of LTP (mediated by GluR1), consistent with our recent finding that GluR2L- and GluR1-mediated potentiation each contribute $\sim 50 \%$ of LTP (Kolleker et al. 2003).

\section{Neuromodulators stimulate Ras signaling and synaptic insertion of GluR2L and GluR1}

Spontaneous synaptic activity in culture slices activates spontaneous Ras activity sufficient to drive synaptic insertion of GluR2L, but not GluR1 (Shi et al. 2001; Zhu et al. 2002). However, GluR1 is delivered into synapses in the intact brain (Mack et al. 2001; Takahashi et al. 2003). Because only LTP-inducing electric stimuli or strong activation of NMDA-Rs/Ras drives synaptic insertion of GluR1 in culture slices (Zhu et al. 2002; Kolleker et al. 2003), we speculated that certain physiological factors, which are missing in culture slices, may potentiate NMDA-R activation and Ras signaling in the intact brain.

To test this idea, we examined whether histamine, a monoamine neuromodulator, is one of such missing factors because histamine is present in the intact brain (Steriade and McCarley 1990), and it potentiates NMDA responses (Bekkers 1993). We expressed GluR1-GFP in hippocampal slices cultured in media containing histamine. GluR1-GFP-expressing neurons cultured in media with histamine had increased rectification compared with nearby nonexpressing neurons (Fig. 7A,B), indicating synaptic insertion of GluR1-GFP. The amplitude of AMPA responses was the same in GluR1-GFP-expressing and nearby nonexpressing neurons (Fig. 7A,B). These results suggest that histamine stimulates synaptic insertion of GluR1 and GluR1-GFP in nonexpressing neurons and expressing neurons to a saturated level. In the presence of additional high $\mathrm{Mg}^{2+}$ (data not shown), APV (to block NMDA-Rs), PD98059, or LY294002 in culture media, GluR1-GFP-expressing and nearby nonexpressing neurons had the same AMPA responses (Fig. 7A,B), indicating a blockade of synaptic insertion of recombinant GluR1-GFP and endogenous GluR1 in expressing and nonexpressing neurons. Neuromodulator receptors potentiate NMDA and Ras responses via activating a Src kinase that phosphorylates NMDA-Rs (Lu et al. 1999). To determine whether Src mediates the histaminestimulated synaptic insertion of GluR1, we included the Src inhibitor, PP2, or its nonfunctional analog, PP3 (Takasu et al. 2002), in culture media. We found that PP2, but not PP3, blocked the histamine-induced synaptic delivery of GluR1 (data not shown). Together, these results suggest that the histamine-stimulated synaptic 
A
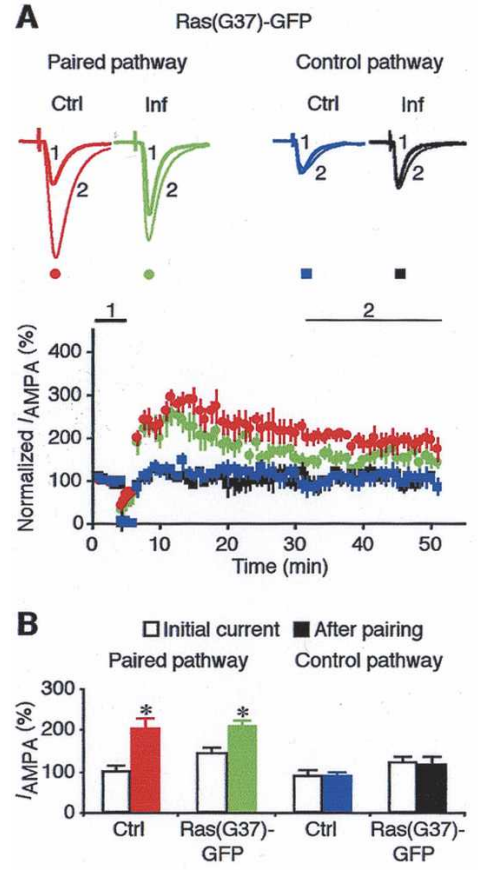

C
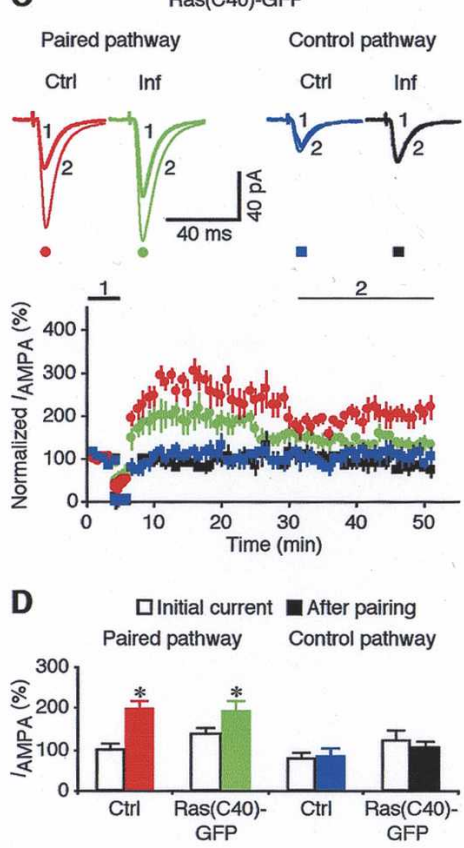

E

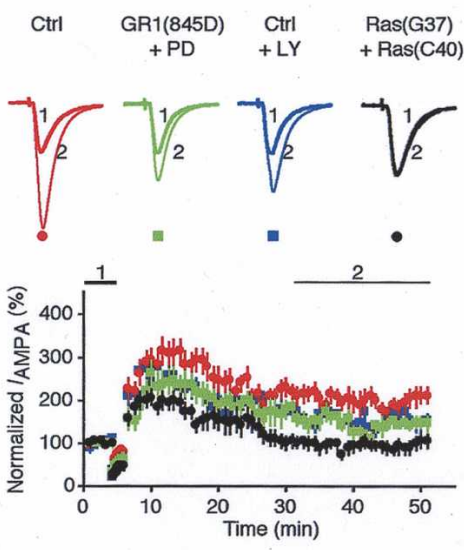

$\mathbf{F}$
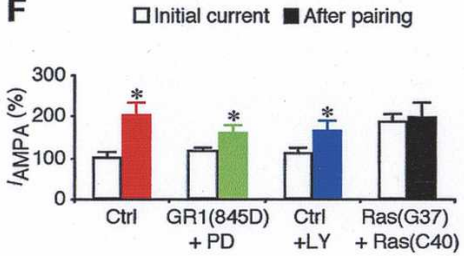

Figure 6. Signaling LTP by Ras-MEK-ERK and Ras-Pi3K-PKB pathways. (A) Average AMPA-R-mediated synaptic responses obtained before $(-60 \mathrm{mV}$, thick trace) and after $(-60 \mathrm{mV}$, thin trace) pairing from a pair of Ras(G37)-GFP-expressing and nearby nonexpressing neurons in paired (upper left; red and green) and control pathway (upper right; blue and black). (Lower plot) Normalized simultaneously evoked responses recorded from neurons expressing or not expressing Ras(G37)-GFP against the time. (B) Steady-state synaptic AMPA response amplitudes in paired $(n=8, p<0.05)$ and control pathways $(n=8, p=0.78)$ in neurons expressing Ras(G37)-GFP and nonexpressing nearby control neurons before and after pairing. $(C)$ Average AMPA-R-mediated synaptic responses obtained before (-60 mV, thick trace) and after $(-60 \mathrm{mV}$, thin trace) pairing from a pair of Ras(C40)-GFP-expressing and nearby nonexpressing neurons in paired (upper left; red and green) and control pathway (upper right; blue and black). (Lower plot) Normalized simultaneously evoked responses recorded from neurons expressing or not expressing Ras(C40)-GFP against the time. $(D)$ Steady-state synaptic AMPA response amplitudes in paired $(n=8, p<0.05)$ and control pathways $(n=8, p=0.53)$ in neurons expressing Ras(C40)-GFP and nonexpressing nearby control neurons before and after pairing. $(E)$ Average AMPA-R-mediated synaptic responses obtained before $(-60 \mathrm{mV}$, thick trace) and after $(-60 \mathrm{mV}$, thin trace) pairing from nonexpressing neurons maintained in normal media (red), GluR1(845D)-GFP-expressing neurons maintained in $25 \mu$ M PD98059 (green), nonexpressing neurons maintained in $25 \mu M$ LY294002 (blue), and Ras(G37)-GFP and Ras(C40)-GFP-coexpressing neurons (black) maintained in normal media. (Lower plot) Normalized simultaneously evoked responses recorded from these neurons against the time. $(F)$ Steady-state synaptic AMPA response amplitudes for GluR1(845D)-GFP-expressing neurons maintained in $25 \mu \mathrm{M}$ PD98059 (ctrl, $n=16 \mathrm{vs.} \mathrm{LY,} n=12$; Mann-Whitney Rank Sum test, $p<0.01$ ), for nonexpressing neurons maintained in $10 \mu \mathrm{M}$ LY294002 (ctrl, $n=16$ vs. LY, $n=10$; Mann-Whitney Rank Sum test, $p<0.05$ ), and for Ras(G37)-GFP and Ras(C40)-GFP-coexpressing neurons maintained in normal media (ctrl, $n=16$ vs. exp, $n=12$; Mann-Whitney Rank Sum test, $p<0.001)$. AMPA-R-mediated current amplitude and standard errors were normalized to average values from control neurons. Asterisk indicates $p<0.05$ (Wilcoxon or Mann-Whitney Rank Sum test).

insertion of GluR1 requires synaptic activation of NMDA-Rs, Src, Ras-MEK-ERK, and Ras-Pi3K-PKB signaling.

To test whether histamine also stimulates the RasMEK-ERK pathway and synaptic insertion of GluR2L, we expressed GluR2L(R $\rightarrow$ Q)-GFP in the presence of histamine. In the presence of histamine, GluR2L/R $\rightarrow$ Q)-GFP-expressing neurons had increased rectification compared with nearby nonexpressing neurons, indicating synaptic insertion of GluR2L(R $\rightarrow$ Q)-GFP in expressing neurons (Fig. 7A,B). In contrast to the nonhistamine condition (Fig. 3B), GluR2L(R $\rightarrow$ Q)-GFP-expressing and nonexpressing neurons had AMPA responses with the same amplitude (Fig. 7A,B). These results suggest that histamine stimulates synaptic insertion of GluR2L and GluR2L(R $\rightarrow$ Q)-GFP in nonexpressing neu- rons and expressing neurons to a saturated level. In the presence of additional high $\mathrm{Mg}^{2+}$ (data not shown), APV or PD98059, but not LY294002, in culture media, GluR2L(R $\rightarrow$ Q)-GFP-expressing and nearby nonexpressing neurons had the same AMPA responses (Fig. $7 \mathrm{~A}, \mathrm{~B})$, indicating no synaptic insertion of recombinant GluR2L(R $\rightarrow$ Q)-GFP or endogenous GluR2L in expressing and nonexpressing neurons. In addition, PP2, a Src inhibitor, but not PP3, a nonfunctional analog, blocked the histamine-induced synaptic delivery of GluR2L (data not shown), suggesting that Src was required for the histamine-stimulated synaptic insertion of GluR2L. Together, these results suggest that the histamine-stimulated synaptic insertion of GluR2L requires synaptic activation of NMDA-Rs, Src, and Ras-MEK-ERK signaling, but not Ras-Pi3K-PKB signaling. 

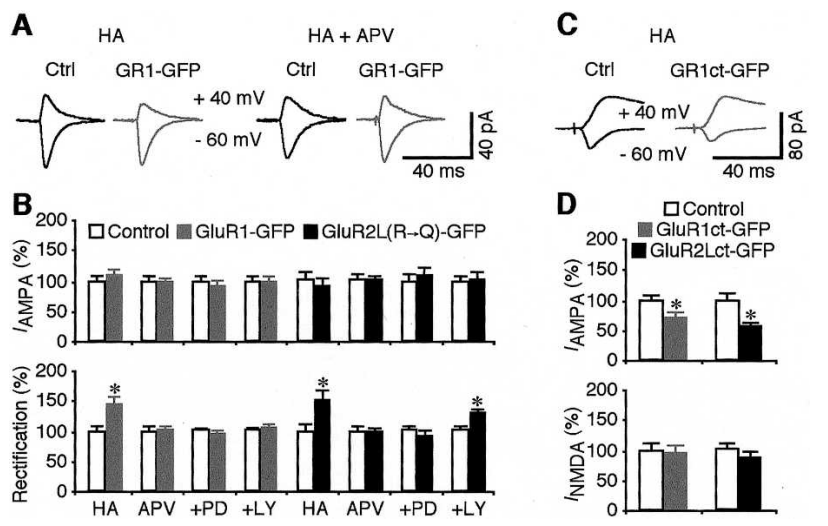

Figure 7. Histamine stimulates synaptic delivery of GluR 1 and GluR2L. (A) Evoked AMPA-R-mediated responses recorded from nonexpressing (Ctrl) and GluR1-GFP-expressing cells cultured in media containing histamine (HA). (B, top) AMPA responses in GluR1-GFP-expressing cells maintained in media containing $75 \mu \mathrm{M}$ histamine $(n=14, p=0.68)$, or with additional $100 \mu \mathrm{M}$ DL-APV $(n=16, p=0.76), 25 \mu \mathrm{M}$ PD98059 $(n=16, p=0.20)$, or $10 \mu \mathrm{M} \mathrm{LY294002}(n=14, p=0.73)$; and GluR2L(R $\rightarrow$ Q)-GFP-expressing cells maintained in media containing $75 \mu \mathrm{M}$ histamine $(n=14, p=0.55)$, or with additional $100 \mu \mathrm{M}$ DL-APV $(n=14, p=0.73), 25 \mu \mathrm{M}$ PD98059 $(n=16$, $p=0.88)$, or $10 \mu \mathrm{M}$ LY294002 $(n=12, p=0.58)$. (Bottom) Rectification of GluR1-GFP-expressing cells maintained in media containing $75 \mu \mathrm{M}$ histamine $(n=14, p<0.005)$, or with additional $100 \mu \mathrm{M}$ DL-APV $(n=16, p=0.88), 25 \mu \mathrm{M}$ PD98059 $(n=16, p=0.54)$, or $10 \mu \mathrm{M}$ LY294002 $(n=14, p=0.59)$; and GluR2L(R $\rightarrow$ Q)-GFP-expressing cells maintained in media containing $75 \mu \mathrm{M}$ histamine $(n=14, p<0.005)$, or with additional $100 \mu \mathrm{M}$ DL-APV $(n=14, p=0.83), 25 \mu \mathrm{M}$ PD98059 $(n=16$, $p=0.38)$, or $10 \mu \mathrm{M}$ LY294002 $(n=12, p<0.005)$. (C) Evoked AMPA-R- and NMDA-R-mediated responses recorded from nonexpressing (Ctrl) and GluR1ct-GFP-expressing cells cultured in media containing histamine. $(D, t o p)$ AMPA responses in cells expressing GluR1ct-GFP $(n=14, p<0.05)$, or GluR2LctGFP $(n=16, p<0.005)$ from slices maintained in media containing $75 \mu \mathrm{M}$ histamine. (Bottom) NMDA responses in cells expressing GluR1ct-GFP $(n=14, p=0.25)$ or GluR2Lct-GFP $(n=16, p=0.23)$ from slices maintained in media containing 75 $\mu M$ histamine. AMPA-R- and NMDA-R-mediated current amplitude, rectification, and standard errors were normalized to average values from control cells. Asterisk indicates $p<0.05$ (Wilcoxon test).

To confirm that histamine stimulates synaptic insertion of endogenous GluR1 and GluR2L in CA1 neurons, we expressed the GFP-tagged cytoplasmic terminus of GluR1 and GluR2L, GluR1ct-GFP and GluR2Lct-GFP, which block synaptic delivery of endogenous GluR1 and GluR2L, respectively (Shi et al. 2001; Kolleker et al. 2003). In the presence of histamine, neurons expressing GluR1ct-GFP or GluR2Lct-GFP had depressed AMPA responses compared with nearby nonexpressing neurons (Fig. 7C,D). NMDA responses did not differ between expressing and nonexpressing neurons. These results indicate that histamine stimulates synaptic insertion of endogenous GluR1 and GluR2L.

To test whether histamine stimulates phosphorylation of ERK, PKB, and AMPA-Rs, we performed Western blot experiments. Western blot analysis showed that histamine stimulated phosphorylated ERK, PKB, and GluR1 (at S845 and S831) in CA1 cells (Supplementary Fig. S3). Together, these results indicate that histamine stimulates synaptic insertion of AMPA-Rs via activating RasMEK-ERK and Ras-Pi3K-PKB pathways.

We wished to know whether acetylcholine receptor also stimulates synaptic insertion of AMPA-Rs, since muscarinic acetylcholine subtype $1(\mathrm{~m} 1)$ receptors stimulate Ras signaling (Mattingly and Macara 1996). We found that $\mathrm{McN}-\mathrm{A}-343(\mathrm{McN})$, a selective $\mathrm{m} 1$ receptor agonist (Micheletti and Schiavone 1990), stimulates synaptic insertion of GluR1 and GluR2L in the same manner as histamine (data not shown). In addition, $\mathrm{McN}$ stimulated phosphorylated ERK, PKB, and GluR1 (at S845 and S831) (data not shown). Collectively, these results suggest that both monoaminergic and cholinergic neuromodulators may stimulate synaptic insertion of AMPA-Rs via activating Ras-MEK-ERK and Ras-Pi3KPKB pathways.

\section{State-dependent activation of Ras pathways and synaptic insertion of GluR2L and GluR1}

The above data indicate that physiological factors, such as neuromodulators, can regulate the levels of Ras activity, which specify downstream MEK-ERK and Pi3K-PKB pathways and differentially control synaptic insertion of GluR1 and GluR2L. To determine whether the same Ras-regulated plasticity occurs in physiological conditions, we examined Ras signaling and synaptic trafficking of AMPA-Rs in sleeping and awake animals since neuromodulator release changes between these states (Steriade and McCarley 1990).

We tested this idea by infecting CA1 neurons in the intact brain in different states. In one set of experiments, GluR1-GFP virus was injected at $\sim 8: 00$ am. After the animals recovered from anesthesia $(\sim 2 \mathrm{~h})$, they were transferred individually to a light-illuminated cage for the following $10 \mathrm{~h}$ during the expression of GluR1-GFP. During this period, these animals were largely inactive and spent most of their time sleeping. At $\sim 8: 00 \mathrm{pm}$, these animals were deeply anesthetized and decapitated, and hippocampi were quickly removed and sliced. Then GluR1-GFP-expressing and nearby nonexpressing neurons were identified and recorded simultaneously in vitro. We found that GluR1-GFP-expressing neurons from sleeping animals had the same AMPA responses compared with nonexpressing neurons (Fig. 8A,B). In another set of experiments, GluR1-GFP virus was injected at $\sim 8: 00 \mathrm{pm}$. After these animals recovered from anesthesia, they were returned to the dam and allowed to play with their littermates. These animals were awake and active in their cage for the most part of the GluR1GFP expression period. At 8:00 am the next morning, hippocampal slices were made from these animals and AMPA responses were recorded and compared between GluR1-GFP-expressing and nearby nonexpressing neurons. GluR1-GFP-expressing neurons from awake animals had increased rectification compared with nonex- 
A
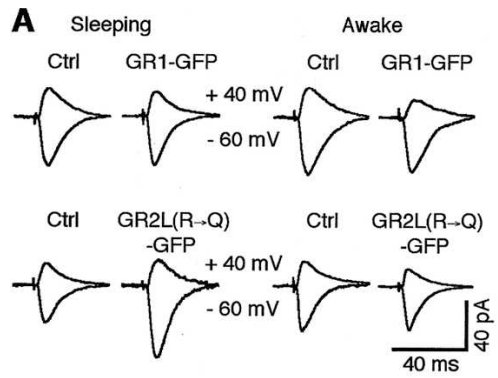

B CControl aGR1-GFP $\square$ GR2L(R $\rightarrow Q)$-GFP
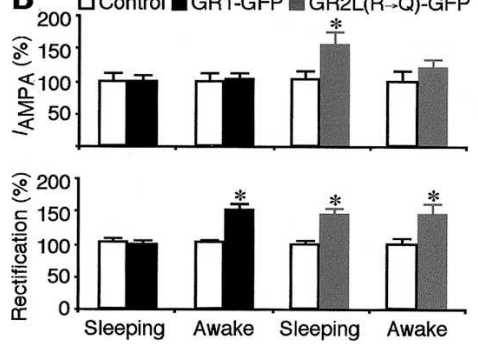

C Sleeping Ctrl GR1ct-GFP

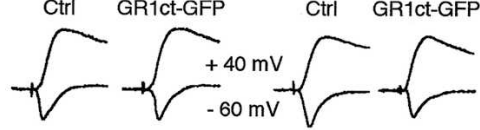

Ctrl GR2Lct-GFP

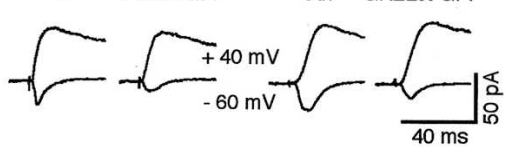

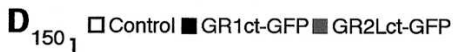
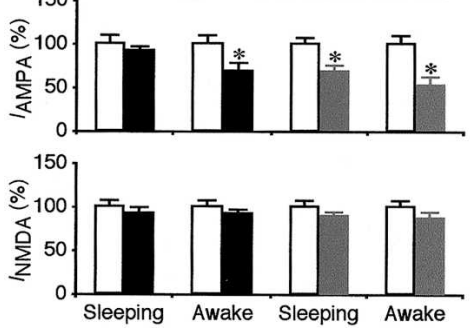

Figure 8. State-dependent synaptic insertion of GluR2L and GluR1. (A) Evoked AMPA-R-mediated responses recorded from nonexpressing (Ctrl) and GluR2L(R $\rightarrow$ Q)-GFP- or GluR1GFP-expressing cells. Animals were kept either in sleeping or awake state during expression of constructs. $(B$, top) AMPA responses in GluR1GFP-expressing cells from sleeping $(n=14$ $p=0.88)$ or awake animals $(n=14, p=0.83)$ and GluR2L(R $\rightarrow$ Q)-GFP-expressing cells from sleeping $(n=11, p<0.05)$ or awake animals $(n=16$, $p=0.12$ ). (Bottom) Rectification of GluR1GFP-expressing cells from sleeping $\mid n=14$, $p=0.59)$ or awake animals $(n=14, p<0.005)$, and GluR2L(R $\rightarrow$ Q)-GFP-expressing cells from sleeping $(n=11, p<0.01)$ or awake animals $(n=16, p<0.005) .(C)$ Evoked AMPA-R- and NMDA-R-mediated responses recorded from nonexpressing (Ctrl) and GluR2Lct-GFP- or GluR1ct-GFP-expressing cells. Animals were kept either in sleeping or awake state during expression of constructs. $(D$, top $)$ AMPA responses in GluR1ct-GFP-expressing cells from sleeping $(n=14, p=0.88)$ or awake animals $(n=14, p<0.01)$, and GluR2Lct-GFP-expressing cells from sleeping $(n=13, p<0.01)$ or awake animals $(n=12, p<0.005)$. (Bottom) NMDA responses in GluR1ct-GFP-expressing cells from sleeping $(n=14, p=0.25)$ or awake animals $(n=14, p=0.43)$, and GluR2Lct-GFP-expressing cells from sleeping $(n=13, p=0.15)$ or awake animals $(n=12, p=0.24)$. AMPA-R- and NMDA-R-mediated current amplitude, rectification, and standard errors were normalized to average values from control cells. Asterisk indicates $p<0.05$ (Wilcoxon test).

pressing neurons (Fig. 8A,B), indicating synaptic insertion of GluR1-GFP in expressing neurons. The amplitude of AMPA responses in GluR1-GFP-expressing and nonexpressing neurons was the same (Fig. 8A,B), indicating saturation of synaptic insertion of GluR1-GFP and GluR1 in expressing and nonexpressing neurons. As a control, another two groups of animals were injected with GluR1-GFP virus at either $\sim 8: 00$ am or $\sim 8: 00 \mathrm{pm}$. These animals were then kept in a state of slow-wave sleep by supplying additional pentobarbital during expression of GluR1-GFP. GluR1-GFP-expressing neurons from these animals had the same AMPA responses compared with nearby nonexpressing neurons $(n=14$, $p=0.73$ for 8:00 am infection; $n=14, p=0.36$ for 8:00 pm infection). Together, these results suggest that synaptic insertion of endogenous GluR1 and recombinant GluR1-GFP occurs only when animals are awake.

We also expressed GluR2L(R $\rightarrow$ Q)-GFP in CA1 neurons in sleeping and awake animals. GluR2L(R $\rightarrow \mathrm{Q})$ GFP-expressing neurons from sleeping animals had enhanced AMPA responses and rectification compared with nearby nonexpressing neurons (Fig. 8A,B). These results indicate that GluR2L(R $\rightarrow \mathrm{Q})$-GFP is driven into synapses in sleeping animals. On the other hand, GluR2L(R $\rightarrow$ Q)-GFP-expressing neurons from awake animals had enhanced rectification compared with nearby nonexpressing neurons (Fig. 8A,B), indicating synaptic insertion of GluR2L-GFP in expressing neurons. The AMPA responses in expressing and nonexpressing neurons from awake animals had the same amplitude (Fig. 8A,B), indicating more synaptic delivery of endogenous GluR2L in nonexpressing neurons and saturation of synaptic delivery of GluR2L(R $\rightarrow$ Q)-GFP and GluR2L in expressing and nonexpressing neurons. To- gether these results indicate that synaptic insertion of endogenous GluR2L and recombinant GluR2L(R $\rightarrow$ Q)GFP occurs in both sleeping and awake animals.

To confirm the synaptic insertion of endogenous GluR1 and GluR2L, we expressed GluR1ct-GFP and GluR2Lct-GFP in the intact brain. We reasoned that expression of GluR1ct-GFP and GluR2Lct-GFP will depress transmission in expressing neurons if there is ongoing synaptic delivery of endogenous GluR1 and GluR2L. Indeed, GluR1ct-GFP-expressing neurons from sleeping animals had the same AMPA responses compared with nearby nonexpressing neurons, while those from awake animals had depressed AMPA responses (Fig. 8C,D). GluR2Lct-GFP-expressing neurons from both sleeping and awake animals had depressed AMPA responses (Fig. 8C,D). To confirm the specificity of GluR1ct-GFP and GluR2Lct-GFP on blocking endogenous GluR1 and GluR2L trafficking, demonstrated previously in vitro (Shi et al. 2001; Kolleker et al. 2003), we repeated the same experiments in the intact brain using GluR1 and GluR2 knockout mice. The depression in GluR1ct-GFP-expressing neurons was selectively blocked in awake GluR1 knockout mice, but not awake GluR2 knockout mice, whereas the depression in GluR2Lct-GFP-expressing neurons was selectively blocked in awake GluR2 knockout mice, but not awake GluR1 knockout mice (Supplementary Fig. S4). Together, these results indicate that GluR2L-dependent, but not GluR1-dependent, synaptic potentiation occurs during sleep, whereas both GluR2L- and GluR1-dependent synaptic potentiations occur during waking.

Consistent with these results, Western blot analysis showed increases in phosphorylated ERK, PKB, S845, and S831 of GluR1 in CA1 cells from awake animals 
Qin et al.

compared with those from sleeping animals (Fig. 9A-D). Collectively, these results indicate that spontaneous Ras-MEK-ERK signaling is sufficient to drive synaptic insertion of GluR2L when animals are asleep, while additional stimulation of Ras-Pi3K-PKB signaling drives synaptic insertion of GluR1 when animals are awake.

\section{Discussion}

In this study, we demonstrated that fine-tuned Ras activity levels control GluR2L- and GluR1-mediated synaptic potentiation by specifying distinct downstream effector pathways (Fig. 9E). The alternation of Ras signaling between sleeping and awake states, presumably regulated by neuromodulators and/or other state-dependent physiological factors, may serve as the cellular and molecular mechanisms for state-dependent learning and memory.

Ras can stimulate multiple signaling pathways via CRaf, B-Raf, Ral, or Pi3K in nonneuronal cells (White et al. 1995; Yamamori et al. 1995; Rodriguez-Viciana et al. 1997). Dependent on cell type, Ras(C40) activates Pi3K, Ras(S35) stimulates ERK via activating C-Raf kinase, and/or Ras(G37) stimulates ERK via activating B-Raf kinase and/or stimulates Ral via association with RalGEF. Here, we report that expressing Ras(G37)-GFP, but not Ras(S35)-GFP, stimulates MEK-ERK activity and potentiates synaptic transmission in hippocampal CA1 cells. Both B-Raf and Ral are expressed at synapses (Husi et al. 2000). However, only B-Raf stimulates ERK signaling, whereas Ral does not (Moodie et al. 1994; Yamamori et al. 1995; Verheijen et al. 1999). Consistent with these findings, Ras(G37)-GFP activates B-Raf activity, but has little effect on Ral and C-Raf activity in CA1 neurons. This lends support to previous findings that B-Raf is expressed at synapses, while C-Raf is present mainly around the nuclei (Mihaly et al. 1993; Morice et al. 1999). Although additional experiments are needed to undoubtedly place B-Raf in the signaling path from Ras to MEKERK in CA1 neurons, these findings certainly suggest it as a possible candidate.

Our results suggest that Ras signals synaptic insertion of AMPA-Rs via stimulating phosphorylation of S845 and S831 of GluR1 and S842 of GluR2L (Fig. 9E). Because Ras downstream signaling molecules ERK and PKB are unlikely to directly phosphorylate GluR1 and GluR2L
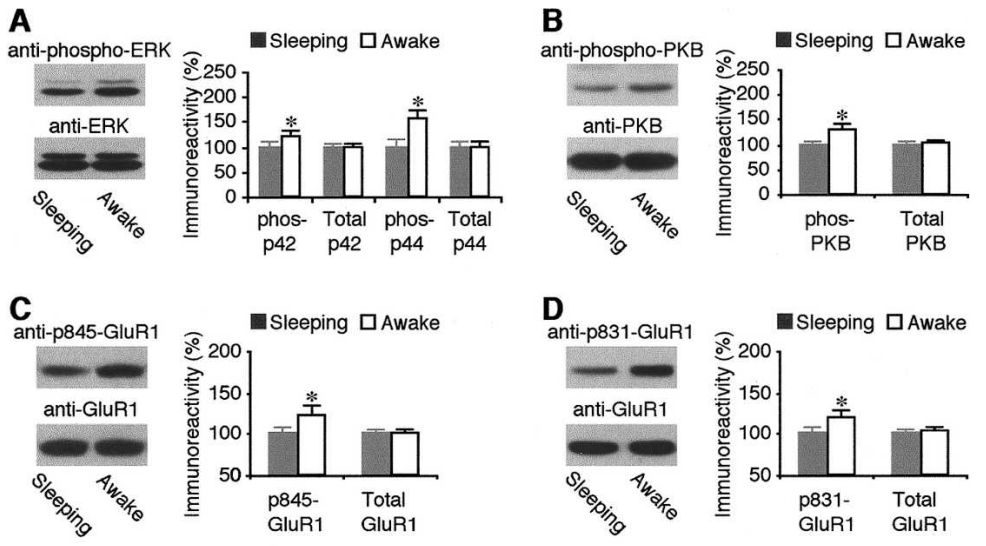

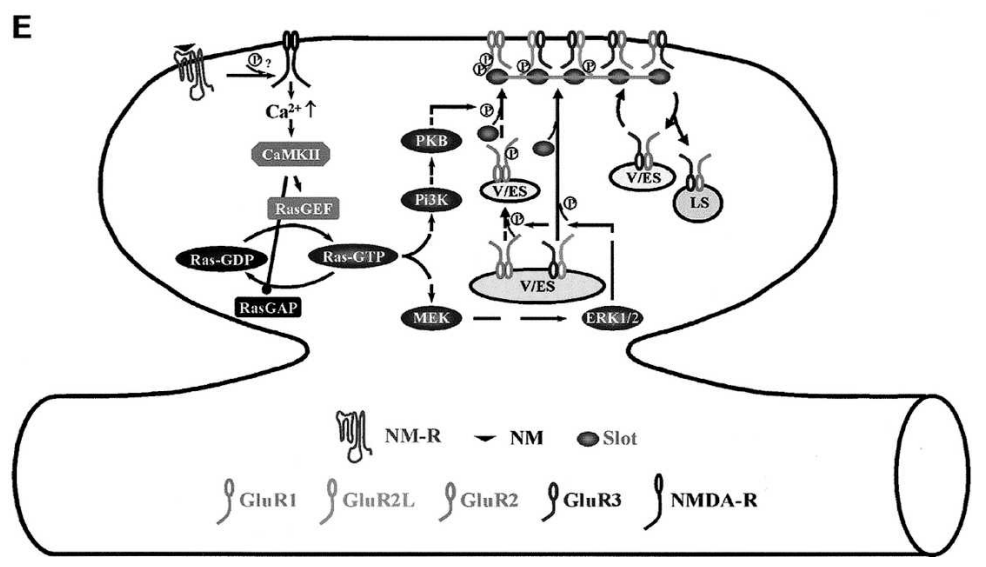

Figure 9. State-dependent activation of Ras-MEKERK and Ras-Pi3K-PKB pathways. (A, left) Western blots of phospho-ERK in hippocampal CAl region prepared from sleeping or awake animals. (Right) Relative amounts of phospho-ERK (i.e., p42 and p44 bands) in hippocampal CA1 region prepared from sleeping and awake animals $(n=13, p<0.05$ for phospho-p42; $n=13, p<0.005$ for phospho-p44). Relative amounts of total ERK (i.e., p42 and p44 bands) in hippocampal CA1 region prepared from sleeping and awake animals $(n=13, p=0.22$ for $\mathrm{p} 42$; $n=13, p=0.28$ for p44). (B, left) Western blots of phospho-PKB in hippocampal CAl region prepared from sleeping or awake animals. (Right) Relative amounts of phospho-PKB in hippocampal CAl region prepared from sleeping and awake animals $(n=9, p<0.01)$. Relative amounts of total PKB in hippocampal CA1 region prepared from sleeping and awake animals $(n=9, p=0.59)$. (C, left $)$ Western blots of phospho-p845-GluR1 in hippocampal CA1 region prepared from sleeping or awake animals. (Right) Relative amounts of phospho-p845-GluR1 in hippocampal CA1 region prepared from sleeping and awake animals $(n=18, p<0.05)$. Relative amounts of total GluR1 in hippocampal CA1 region prepared from sleeping and awake animals $(n=18, p=0.37)$. $(D$, left $)$ Western blots of phospho-p831-GluR1 in control hippocampal CA1 region prepared from sleeping or awake animals. (Right) Relative amounts of phospho-p831-GluR1 in hippocampal CA1 region prepared from sleeping and awake animals $\mid n=15$, $p<0.05)$. Relative amounts of total GluR1 in hippocampal CA1 region prepared from sleeping and awake animals $(n=15, p=0.78)$. Each lane was loaded with the same amount of protein $(120 \mu \mathrm{g})$. The relative values and standard errors were normalized to average amounts of phospho-ERK, phospho-PKB, phospho-p831-GluR1, and phospho-p845-GluR1, or total ERK, total PKB, and GluR1 from hippocampal CA1 region prepared from sleeping animals. Asterisk indicates $p<0.05$ (Wilcoxon test). (E) Model for state-dependent Ras signaling and synaptic trafficking of AMPA-Rs. (LS) Lysosome; (V/ES) vesicles/endosomes; (NM) neuromodulator; (NM-R) neuromodulator receptor. 
(Kyriakis and Avruch 2001; Vivanco and Sawyers 2002), other molecules probably exist at synapses to relay the signaling. Two likely candidates are cAMP-dependent protein kinase (PKA) and calcium/calmodulin-dependent protein kinase II (CaMKII), since they can phosphorylate S845 and S831 of GluR1, respectively (Song and Huganir 2002). Protein kinase C (PKC) is another putative candidate because it can phosphorylate $\mathrm{S} 831$, as well as S845, albeit to a lesser extent (Blackstone et al. 1994; Mammen et al. 1997). However, whether ERK and PKB stimulate PKA, CaMKII, and/or PKC remains to be examined. On the other hand, serine/threonine kinases Rsk and mTOR-S6K, which relay downstream Ras signaling in nonneuronal cells (Kyriakis and Avruch 2001; Vivanco and Sawyers 2002), may also serve as the relays. In particular, both Rsk and mTOR are expressed at synapses, and disruption of Rsk and mTOR signaling leads to mental retardation (Trivier et al. 1996; Yntema et al. 1999; Husi et al. 2000; Tang et al. 2002; Tee et al. 2003). Thus, determining the precise functional relationships (i.e., sequential or parallel, and downstream or upstream) of the signaling molecules involved in Ras pathways during LTP is central to answer many important questions related to the mechanisms of synaptic plasticity (Thomas and Huganir 2004).

Whether MAPK pathways work independently or cross-talk in nonneuronal cells is somewhat controversial. NMDA-R-dependent LTP, long-term depression (LTD), and depotentiation, which play key roles in the bidirectional control of neuronal synaptic strength, require MAPK signaling. Recent studies showed that LTP, LTD, and depotentiation are triggered by distinct NMDA-Rs (i.e., NR2A- and NR2B-containing NMDARs) (Liu et al. 2004; Massey et al. 2004; Zhu et al. 2005), mediated by different Ras family GTPase-MAPK signaling pathways (i.e., Ras-ERK, Rap1-p38 MAPK, and Rap2JNK) and specific aspects of AMPA-R trafficking (i.e., synaptic insertion and removal of AMPA-Rs with different cytoplasmic termini) (Zhu et al. 2002, 2005), and that they utilize special pools of endosomes (i.e., recycling and late endosomes) (Luscher et al. 1999; Ehlers 2000; Lee et al. 2004; Park et al. 2004; Brown et al. 2005). These results suggest that independent molecular and cellular processes mediate different forms of synaptic plasticity. Here we report that Ras differentially signals GluR2Land GluR1-mediated LTP via diverging signaling into ERK and Pi3K pathways in CAl neurons (Fig. 9E). In nonneuronal cells, some studies show that ERK and Pi3K pathways may inhibit or potentiate the other (Lopez-Ilasaca et al. 1997; Rommel et al. 1999), while other studies indicate that these two pathways signal cellular processes independently although the basal activity of one kinase may play a permissive role for the other (White et al. 1995; Dudek et al. 1997; RodriguezViciana et al. 1997; Wennstrom and Downward 1999). We show that activation of Ras-MEK-ERK and RasPi3K-PKB pathways by expressing Ras(G37)-GFP and Ras(C40)-GFP each accounts for an $-50 \%$ increase of synaptic transmission and LTP. In addition, Ras(G37)GFP-mediated synaptic potentiation is selectively blocked in GluR2 knockout mice. In contrast, Ras(C40)GFP-mediated potentiation is selectively blocked in GluR1 knockout mice. Moreover, the Ras-MEK-ERK pathway signals phosphorylation of S845 of GluR1, whereas the Ras-Pi3K-PKB pathway signals phosphorylation of S831 of GluR1. Finally, activation of Ras-MEKERK and Ras-Pi3K-PKB requires different levels of synaptic activity or neuromodulator receptor activity. Because of the distinct molecular regulators and relays, targets of signaling, and functional effects, our data are consistent with the notion that Ras-MEK-ERK and RasPi3K-PKB pathways function independently at synapses.

Although NMDA-R-dependent forms of synaptic plasticity have been extensively examined in vitro, little is known about their properties in the intact brain. Previous studies have shown that both the occurrence and magnitude of LTP induced by electric tetanization stimuli are higher in awake than sleeping animals (Leonard et al. 1987; Bramham and Srebro 1989). However, the mechanisms of this state-dependent LTP are unclear, because the LTP-inducing stimuli do not mimic physiological activity in these states (Buzsaki et al. 2002). Both GluR2L and GluR1 mediate LTP in juvenile and adult animals (Zamanillo et al. 1999; Kolleker et al. 2003). We report here that synaptic activity in sleeping animals is sufficient for driving GluR2L but not GluR1 into synapses, whereas synaptic activity in awake animals drives more GluR2L as well as GluR1 into synapses, suggesting more synaptic plasticity in awake animals (Fig. 9E). Based on these findings, we propose that state-dependent physiological factors, such as neuromodulators, may control the state-dependent plasticity. Indeed, neuromodulator agonists can drive more GluR2L as well as GluR1 into synapses, by stimulating Ras signaling. These results are consistent with the previous findings that neuromodulators, whose release increases in general during the awake behavioral state (Steriade and McCarley 1990), stimulate ERK and Pi3K signaling and potentiate LTP (Kobayashi et al. 1997; Murga et al. 1998; Winder et al. 1999; Huang et al. 2004). It remains to be determined whether other state-dependent factors (i.e., neuronal firing patterns, hormones, and neurotrophic factors) regulate synaptic plasticity and how these factors interact in the intact brain.

Memory consolidation seems to occur during sleep and waking, while learning occurs in the conscious state (Hobson and Pace-Schott 2002; Gais and Born 2004). It is believed that the learning and memory processes require synaptic plasticity. We show here that synaptic potentiation is present in both sleeping and awake states. Interestingly, synaptic plasticity in sleeping and awake states is controlled by different levels of Ras signaling and mediated by trafficking of distinct AMPA-Rs. The obvious puzzles are whether and how Ras-regulated, subunit-specific AMPA-R trafficking correlates with the different forms of memory consolidation and learning (e.g., declarative vs. procedural or explicit vs. implicit). Manipulating Ras signaling and trafficking of AMPA-Rs in intact animals (e.g., in vivo expression of Ras mutants and GluRct-GFP) (see also Rumpel et al. 2005) during 
different behavioral states (e.g., slow-wave sleep, REM sleep, quiescent alert, and active exploring) and monitoring changes in learning and memory behavior promise to reveal new insights into these pivotal questions.

\section{Materials and methods}

\section{Biochemical analyses}

Hippocampal extracts were prepared by homogenizing hippocampal CA1 regions isolated from either cultured slices or 2-wk-old rat brains (Zhu et al. 2000, 2002). To isolate the CA1 regions from intact rat brains, hippocampi were quickly isolated and frozen with liquid $\mathrm{N}_{2}$, and CA1 regions were isolated from frozen hippocampi immediately before homogenization. The expression efficacy of recombinant proteins in these experiments was high ( $>95 \%$ of CA1 neurons). Homogenizing solution contained HEPES $10 \mathrm{mM}, \mathrm{NaCl} 150 \mathrm{mM}$, EDTA $10 \mathrm{mM}$, EGTA $4 \mathrm{mM}$, PMSF $0.2 \mathrm{mM}$, NaPPi $0.1 \mathrm{mM}$, NaF $0.5 \mathrm{mM}$, $\mathrm{Na}_{3} \mathrm{VO}_{4} 1 \mathrm{mM}$, chymostatin $0.0001 \%$, leupeptin $0.0001 \%$, antipain $0.0001 \%$, pepstatin $0.0001 \%$, and Triton $1 \%$. To dephosphorylate C-Raf, hippocampal extracts were treated with $\lambda$ protein phosphatase (New England Biolab) for $1 \mathrm{~h}$ at $30^{\circ} \mathrm{C}$. Membranes were blotted with anti-phospho-ERK (1:10,000; Cell Signaling Technology), anti-phospho-PKB (1:2000; Cell Signaling), anti-phospho-p845-GluR1 (1:800; Chemicon), anti-phospho-p831-GluR1 (1:1000; Chemicon), anti-phospho-p601-B-Raf (1:1000; a gift from Andrea Borton at Cell Signaling, Beverly, MA) (Zhang and Guan 2000), or anti-phospho-p338-C-Raf (1: 1000; Cell Signaling) antibody; stripped; and reblotted with anti-ERK (1:2000; Cell Signaling), anti-PKB (1:1000; Cell Signaling), anti-GluR1 (1:8000; Chemicon), anti-B-Raf (1:1000; Santa Cruz Biotechnology), or anti-C-Raf (1:1000; Santa Cruz) antibody. Active Ral was detected by affinity precipitation of RalGTP with GST-linked Ral-binding domain, GST-RalBD, as described in a previous report (Wolthuis et al. 1998). The bound Ral-GTP was then eluted and Western blotted with anti-Ral antibody (1:5000; Transduction Laboratories). Western blots were quantified by chemiluminescence and densitometric scanning of the films under linear exposure conditions.

\section{Constructs of recombinant receptors and expression}

The Ras mutant constructs $\mathrm{T} 35 \rightarrow \mathrm{S}$ [Ras(S35)-GFP], E37 $\rightarrow \mathrm{G}$ [Ras(G37)-GFP], and Y40 $\rightarrow \mathrm{C}$ [Ras(C40)-GFP] were generated from a constitutively active Ras(V12) background (White et al. 1995; Rodriguez-Viciana et al. 1997) using the Quick Change Site-Directed mutagenesis kit (Stratagene). To mimic the phosphorylation at the crucial serine sites at GluR1 and GluR2L cytoplasmic termini, point mutants were made at GluR1-GFP cytoplasmic termini S831 $\rightarrow$ D to generate GluR1(831D)-GFP, $\mathrm{S} 845 \rightarrow \mathrm{D}$ to generate GluR1(845D)-GFP, S831 $\rightarrow$ D and S845 $\rightarrow$ $\mathrm{D}$ to generate GluR1(DD)-GFP, or at GluR2L(R $\rightarrow$ Q)-GFP cytoplasmic termini, S841 $\rightarrow$ D, to generate GluR2L(841D)-GFP. Other constructs were made as previously described (Zhu et al. 2000, 2002). Constructs were expressed in CA1 neurons in hippocampal slices or in intact brains, using Sindbis virus or biolistics transfection. For in vitro expression, slices were prepared from post-natal 6-7-d-old rats or mice, infected with virus or transfected using a gene gun after 6-8 $\mathrm{d}$ in vitro, and incubated on culture media and $5 \% \mathrm{CO}_{2}$ for $15 \pm 3 \mathrm{~h}$ before experiments. To determine the expression of all cotransfected proteins, we cotransfected RFP- and YFP-tagged Ras mutants with GFP-tagged GluRs. All transfected neurons displayed RFP, YFP, and GFP fluorescence ( $n=43$; Supplementary Fig. S5), suggesting that biolistics transfection was efficient to get all cotransfected proteins expressed. For pharmacological experiments, slices were maintained in culture media containing drugs from the time they were infected or transfected. HeLa cells were infected with virus for $15 \pm 3 \mathrm{~h}$ before they were collected, homogenized, and Western blotted. For in vivo expression, postnatal 13-15-d-old rats were initially anesthetized by an intraperitoneal injection of ketamine and xylaxine $(10$ and $2 \mathrm{mg} / \mathrm{kg}$, respectively). Animals were then placed in a stereotaxic frame, and a hole $\sim 1 \times 1 \mathrm{~mm}$ was opened above the right somatosensory cortex (Zhu and Connors 1999). A glass pipette was used to penetrate into the hippocampus according to stereotaxic coordinates, and $\sim 100 \mathrm{~nL}$ of viral solution was delivered into the CA1 region by pressure injection. After the injection, the animals were allowed to recover from the anesthesia and then kept asleep or awake. Some of the animals were kept in a state of slow-wave general anesthesia for $12 \mathrm{~h}$ after virus injection. The sleeping state was determined by monitoring the cortical electroencephalogram (EEG) and maintained by supplying additional doses $(10 \mathrm{mg} / \mathrm{kg}$ of pentobarbital) whenever necessary (Zhu and Connors 1999). Twelve hours after the injections, hippocampi were isolated and hippocampal slices were prepared. Expression of Ras mutants longer than $24 \mathrm{~h}$ also induced nonspecific effects on NMDA-R-mediated responses, changed the resting membrane potential and the membrane time constant, and altered dendritic and spine morphology (Wu et al. 2001; Zhu et al. 2002). Thus, to minimize activation of multiple or nonspecific pathways due to excessive overexpression of recombinant proteins and/or prolonged activation of Ras signaling pathways (e.g., autocrine/paracrine effects; see McCarthy et al. 1995), we preformed all experiments within $18 \mathrm{~h}$ after infection or transfection, during which time no autocrine/paracrine effect on ERK and PKB was observed (Supplementary Fig. S6).

\section{Electrophysiology}

Simultaneous whole-cell recordings were obtained from nearby infected/transfected and noninfected/nontransfected CA1 neuron pairs (Zhu et al. 2000; Larkum and Zhu 2002) under visual guidance using fluorescence and transmitted light illumination with two Axopatch-200B amplifiers (Axon Instruments). The bath solution $\left(29^{\circ} \mathrm{C} \pm 1.5^{\circ} \mathrm{C}\right)$, unless otherwise stated, contained $\mathrm{NaCl} 119 \mathrm{mM}, \mathrm{KCl} 2.5 \mathrm{mM}, \mathrm{CaCl}_{2} 4 \mathrm{mM}, \mathrm{MgCl}_{2} 4 \mathrm{mM}$, $\mathrm{NaHCO}_{3} 26 \mathrm{mM}, \mathrm{NaH}_{2} \mathrm{PO}_{4} 1 \mathrm{mM}$, glucose $11 \mathrm{mM}$, picrotoxin $0.1 \mathrm{mM}$, bicuculline $0.01 \mathrm{mM}$, and 2-chloroadenosine 0.002 $\mathrm{mM}(\mathrm{pH} 7.4)$, and gassed with $5 \% \mathrm{CO}_{2} / 95 \% \mathrm{O}_{2}$. 2-chloroadenosine was included to prevent bursting. For experiments in which slices were maintained in culture with PD98059, LY294002, PP2, and PP3 (Calbiochem), these drugs were included during recordings. Patch recording pipettes $(3-6 \mathrm{M} \Omega)$ contained cesium methanesulfonate $115 \mathrm{mM}, \mathrm{CsCl} 20 \mathrm{mM}$, HEPES $10 \mathrm{mM}$, $\mathrm{MgCl}_{2} 2.5 \mathrm{mM}, \mathrm{Na}_{2} \mathrm{ATP} 4 \mathrm{mM}, \mathrm{Na}_{3} \mathrm{GTP} 0.4 \mathrm{mM}$, sodium phosphocreatine $10 \mathrm{mM}$, EGTA $0.6 \mathrm{mM}$, and spermine $0.1 \mathrm{mM} / \mathrm{pH}$ 7.25). Synaptic responses were evoked by bipolar electrodes with single voltage pulses $(200 \mu \mathrm{sec}$, up to $20 \mathrm{~V}$ ) placed in the stratum radiatum $\sim 300-500 \mu \mathrm{m}$ from the CAl cells. Synaptic AMPA responses at $-60 \mathrm{mV}$ and $+40 \mathrm{mV}$ were averaged over 90 trials and their ratio was used as an index of rectification. To minimize the effect from AMPA responses, the peak NMDA responses at $+40 \mathrm{mV}$ were measured after digital subtraction of estimated AMPA responses at $+40 \mathrm{mV}$. LTP was induced by a pairing protocol using 200 pulses at $2 \mathrm{~Hz}$ at $-5 \mathrm{mV}$ within $5 \mathrm{~min}$ after formation of whole-cell configuration. Slices were incubated in a solution containing $25 \mu \mathrm{M}$ PD98059 or $10 \mu \mathrm{M}$ LY294002 before (for at least $1 \mathrm{~h}$ ) and during LTP experiments. 
All results are reported as mean \pm s.e.m., and statistical differences of the means were determined using Wilcoxon and MannWhitney Rank Sum nonparametric tests for paired and unpaired samples, respectively. The level of significance was set at $p<0.05$.

\section{Acknowledgments}

We thank Drs. Jim Garrison, Kun-Liang Guan, John Lawrence, Ian Macara, and Robert Malinow, and members of the Zhu laboratory for critical comments and discussions; Drs. Johannes Bos, José Esteban, Yasunori Hayashi, Atsushi Miyawaki, and Pavel Osten for RalBD, GluR1-GFP, GluR1ct-GFP, YFP (Venus), and GluR2Lct-GFP constructs; and Drs. Zhengping Jia, Rob Kalb, and Peter Seeburg for providing GluR1 and GluR2 knockout mice. This study is supported in part by the Fraxa Research Foundation, NIH, Rett Syndrome Research Foundation, and Whitehall Foundation. J.J.Z is an Alfred P. Sloan Fellow.

\section{References}

Bekkers, J.M. 1993. Enhancement by histamine of NMDA-mediated synaptic transmission in the hippocampus. Science 261: 104-106.

Blackstone, C., Murphy, T.H., Moss, S.J., Baraban, J.M., and Huganir, R.L. 1994. Cyclic AMP and synaptic activity-dependent phosphorylation of AMPA-preferring glutamate receptors. J. Neurosci. 14: 7585-7593.

Bos, J.L. 1995. A target for phosphoinositide 3-kinase: Akt/PKB. Trends Biochem. Sci. 20: 441-442.

Bramham, C.R. and Srebro, B. 1989. Synaptic plasticity in the hippocampus is modulated by behavioral state. Brain Res. 493: 74-86.

Bredt, D.S. and Nicoll, R.A. 2003. AMPA receptor trafficking at excitatory synapses. Neuron 40: 361-379.

Brown, T.C., Tran, I.C., Backos, D.S., and Esteban, J.A. 2005. NMDA receptor-dependent activation of the small GTPase Rab5 drives the removal of synaptic AMPA receptors during hippocampal LTD. Neuron 45: 81-94.

Buzsaki, G., Csicsvari, J., Dragoi, G., Harris, K., Henze, D., and Hirase, H. 2002. Homeostatic maintenance of neuronal excitability by burst discharges in vivo. Cereb. Cortex 12: 893899.

Comings, D.E., Wu, S., Chiu, C., Muhleman, D., and Sverd, J. 1996. Studies of the c-Harvey-Ras gene in psychiatric disorders. Psychiatry Res. 63: 25-32.

Costa, R.M., Federov, N.B., Kogan, J.H., Murphy, G.G., Stern, J., Ohno, M., Kucherlapati, R., Jacks, T., and Silva, A.J. 2002. Mechanism for the learning deficits in a mouse model of neurofibromatosis type 1. Nature 415: 526-530.

Datta, S.R., Brunet, A., and Greenberg, M.E. 1999. Cellular survival: A play in three Akts. Genes \& Dev. 13: 2905-2927.

Davies, S.P., Reddy, H., Caivano, M., and Cohen, P. 2000. Specificity and mechanism of action of some commonly used protein kinase inhibitors. Biochem. J. 351: 95-105.

Dingledine, R., Borges, K., Bowie, D., and Traynelis, S.F. 1999. The glutamate receptor ion channels. Pharmacol. Rev. 51: 7-61.

Dudek, H., Datta, S.R., Franke, T.F., Birnbaum, M.J., Yao, R., Cooper, G.M., Segal, R.A., Kaplan, D.R., and Greenberg, M.E. 1997. Regulation of neuronal survival by the serinethreonine protein kinase Akt. Science 275: 661-665.

Dudley, D.T., Pang, L., Decker, S.J., Bridges, A.J., and Saltiel, A.R. 1995. A synthetic inhibitor of the mitogen-activated protein kinase cascade. Proc. Natl. Acad. Sci. 92: 7686-7689.

Ehlers, M.D. 2000. Reinsertion or degradation of AMPA receptors determined by activity-dependent endocytic sorting. Neuron 28: 511-525.

Gais, S. and Born, J. 2004. Declarative memory consolidation: Mechanisms acting during human sleep. Learn. Mem. 11: 679-685.

Grewal, S.S., York, R.D., and Stork, P.J. 1999. Extracellularsignal-regulated kinase signalling in neurons. Curr. Opin. Neurobiol. 9: 544-553.

Hayashi, Y., Shi, S.H., Esteban, J.A., Piccini, A., Poncer, J.C., and Malinow, R. 2000. Driving AMPA receptors into synapses by LTP and CaMKII: Requirement for GluR1 and PDZ domain interaction. Science 287: 2262-2267.

Hestrin, S., Nicoll, R.A., Perkel, D.J., and Sah, P. 1990. Analysis of excitatory synaptic action in pyramidal cells using wholecell recording from rat hippocampal slices. J. Physiol. (Lond.) 422: 203-225.

Hobson, J.A. and Pace-Schott, E.F. 2002. The cognitive neuroscience of sleep: Neuronal systems, consciousness and learning. Nat. Rev. Neurosci. 3: 679-693.

Hollmann, M. and Heinemann, S. 1994. Cloned glutamate receptors. Annu. Rev. Neurosci. 17: 31-108.

Huang, Y.Y., Simpson, E., Kellendonk, C., and Kandel, E.R. 2004. Genetic evidence for the bidirectional modulation of synaptic plasticity in the prefrontal cortex by D1 receptors. Proc. Natl. Acad. Sci. 101: 3236-3241.

Husi, H., Ward, M.A., Choudhary, J.S., Blackstock, W.P., and Grant, S.G. 2000. Proteomic analysis of NMDA receptoradhesion protein signaling complexes. Nat. Neurosci. 3: 661-669.

Inoki, K., Zhu, T., and Guan, K.L. 2003. TSC2 mediates cellular energy response to control cell growth and survival. Cell 115: 577-590.

Kim, M.J., Dunah, A.W., Wang, Y.T., and Sheng, M. 2005. Differential roles of NR2A- and NR2B-containing NMDA receptors in Ras-ERK signaling and AMPA receptor trafficking. Neuron 46: 745-760.

Kobayashi, M., Ohno, M., Shibata, S., Yamamoto, T., and Watanabe, S. 1997. Concurrent blockade of $\beta$-adrenergic and muscarinic receptors suppresses synergistically long-term potentiation of population spikes in the rat hippocampal CA1 region. Brain Res. 777: 242-246.

Kolleker, A., Zhu, J.J., Schupp, B.J., Qin, Y., Mack, V., Borchardt, T., Kohr, G., Malinow, R., Seeburg, P.H., and Osten, P. 2003. Glutamatergic plasticity by synaptic delivery of GluRB(long)-containing AMPA receptors. Neuron 40: 1199-1212.

Krapivinsky, G., Krapivinsky, L., Manasian, Y., Ivanov, A., Tyzio, R., Pellegrino, C., Ben-Ari, Y., Clapham, D.E., and Medina, I. 2003. The NMDA receptor is coupled to the ERK pathway by a direct interaction between NR2B and RasGRF1. Neuron 40: 775-784.

Kyriakis, J.M. and Avruch, J. 2001. Mammalian mitogen-activated protein kinase signal transduction pathways activated by stress and inflammation. Physiol. Rev. 81: 807-869.

Larkum, M.E. and Zhu, J.J. 2002. Signaling of layer 1 and whisker-evoked $\mathrm{Ca}^{2+}$ and $\mathrm{Na}+$ action potentials in distal and terminal dendrites of rat neocortical pyramidal neurons in vitro and in vivo. J. Neurosci. 22: 6991-7005.

Lee, H.K., Barbarosie, M., Kameyama, K., Bear, M.F., and Huganir, R.L. 2000. Regulation of distinct AMPA receptor phosphorylation sites during bidirectional synaptic plasticity. Nature 405: 955-959.

Lee, S.H., Simonetta, A., and Sheng, M. 2004. Subunit rules governing the sorting of internalized AMPA receptors in hippocampal neurons. Neuron 43: 221-236. 
Leonard, B.J., McNaughton, B.L., and Barnes, C.A. 1987. Suppression of hippocampal synaptic plasticity during slowwave sleep. Brain Res. 425: 174-177.

Liu, L., Wong, T.P., Pozza, M.F., Lingenhoehl, K., Wang, Y., Sheng, M., Auberson, Y.P., and Wang, Y.T. 2004. Role of NMDA receptor subtypes in governing the direction of hippocampal synaptic plasticity. Science 304: 1021-1024.

Lopez-Ilasaca, M., Crespo, P., Pellici, P.G., Gutkind, J.S., and Wetzker, R. 1997. Linkage of G protein-coupled receptors to the MAPK signaling pathway through PI 3-kinase $\gamma$. Science 275: 394-397.

Lu, W.Y., Xiong, Z.G., Lei, S., Orser, B.A., Dudek, E., Browning, M.D., and MacDonald, J.F. 1999. G-protein-coupled receptors act via protein kinase $\mathrm{C}$ and Src to regulate NMDA receptors. Nat. Neurosci. 2: 331-338.

Luscher, C., Xia, H., Beattie, E.C., Carroll, R.C., von Zastrow, M., Malenka, R.C., and Nicoll, R.A. 1999. Role of AMPA receptor cycling in synaptic transmission and plasticity. Neuron 24: 649-658.

Mack, V., Burnashev, N., Kaiser, K.M., Rozov, A., Jensen, V., Hvalby, O., Seeburg, P.H., Sakmann, B., and Sprengel, R. 2001. Conditional restoration of hippocampal synaptic potentiation in Glur-A-deficient mice. Science 292: 25012504.

Malinow, R. and Malenka, R.C. 2002. AMPA receptor trafficking and synaptic plasticity. Annu. Rev. Neurosci. 25: 103126.

Mammen, A.L., Kameyama, K., Roche, K.W., and Huganir, R.L. 1997. Phosphorylation of the $\alpha$-amino-3-hydroxy-5-methylisoxazole4-propionic acid receptor GluR1 subunit by calcium/calmodulin-dependent kinase II. I. Biol. Chem. 272: 32528-32533.

Man, H.Y., Wang, Q., Lu, W.Y., Ju, W., Ahmadian, G., Liu, L., D'Souza, S., Wong, T.P., Taghibiglou, C., Lu, J., et al. 2003. Activation of PI3-kinase is required for AMPA receptor insertion during LTP of mEPSCs in cultured hippocampal neurons. Neuron 38: 611-624.

Massey, P.V., Johnson, B.E., Moult, P.R., Auberson, Y.P., Brown, M.W., Molnar, E., Collingridge, G.L., and Bashir, Z.I. 2004. Differential roles of NR2A and NR2B-containing NMDA receptors in cortical long-term potentiation and long-term depression. J. Neurosci. 24: 7821-7828.

Mattingly, R.R. and Macara, I.G. 1996. Phosphorylation-dependent activation of the Ras-GRF/CDC25Mm exchange factor by muscarinic receptors and G-protein $\beta \gamma$ subunits. Nature 382: $268-272$.

McCarthy, S.A., Samuels, M.L., Pritchard, C.A., Abraham, J.A., and McMahon, M. 1995. Rapid induction of heparin-binding epidermal growth factor/diphtheria toxin receptor expression by Raf and Ras oncogenes. Genes \& Dev. 9: 1953-1964.

Micheletti, R. and Schiavone, A. 1990. Functional determination of McN-A-343 affinity for M1 muscarinic receptors. J. Pharmacol. Exp. Ther. 253: 310-314.

Mihaly, A., Endresz, V., Oravecz, T., Rapp, U.R., and Kuhnt, U. 1993. Immunohistochemical detection of raf protein kinase in cerebral cortical areas of adult guinea pigs and rats. Brain Res. 627: 225-238.

Moodie, S.A., Paris, M.J., Kolch, W., and Wolfman, A. 1994. Association of MEK1 with p21ras.GMPPNP is dependent on B-Raf. Mol. Cell. Biol. 14: 7153-7162.

Morice, C., Nothias, F., Konig, S., Vernier, P., Baccarini, M., Vincent, J.D., and Barnier, J.V. 1999. Raf-1 and B-Raf proteins have similar regional distributions but differential subcellular localization in adult rat brain. Eur. J. Neurosci. 11: 19952006.

Murga, C., Laguinge, L., Wetzker, R., Cuadrado, A., and Gut- kind, J.S. 1998. Activation of Akt/protein kinase B by G protein-coupled receptors. A role for $\alpha$ and $\beta \gamma$ subunits of heterotrimeric $\mathrm{G}$ proteins acting through phosphatidylinositol3-OH kinasey. J. Biol. Chem. 273: 19080-19085.

Opazo, P., Watabe, A.M., Grant, S.G., and O'Dell, T.J. 2003. Phosphatidylinositol 3-kinase regulates the induction of long-term potentiation through extracellular signal-related kinase-independent mechanisms. I. Neurosci. 23: 36793688.

Park, M., Penick, E.C., Edwards, J.G., Kauer, J.A., and Ehlers, M.D. 2004. Recycling endosomes supply AMPA receptors for LTP. Science 305: 1972-1975.

Passafaro, M., Piech, V., and Sheng, M. 2001. Subunit-specific temporal and spatial patterns of AMPA receptor exocytosis in hippocampal neurons. Nat. Neurosci. 4: 917-926.

Rao, A. and Craig, A.M. 1997. Activity regulates the synaptic localization of the NMDA receptor in hippocampal neurons. Neuron 19: 801-812.

Rodriguez-Viciana, P., Warne, P.H., Khwaja, A., Marte, B.M., Pappin, D., Das, P., Waterfield, M.D., Ridley, A., and Downward, J. 1997. Role of phosphoinositide 3-OH kinase in cell transformation and control of the actin cytoskeleton by Ras. Cell 89: 457-467.

Rommel, C., Clarke, B.A., Zimmermann, S., Nunez, L., Rossman, R., Reid, K., Moelling, K., Yancopoulos, G.D., and Glass, D.J. 1999. Differentiation stage-specific inhibition of the Raf-MEK-ERK pathway by Akt. Science 286: 17381741.

Rumpel, S., LeDoux, J., Zador, A., and Malinow, R. 2005. Postsynaptic receptor trafficking underlying a form of associative learning. Science 308: 83-88.

Sanna, P.P., Cammalleri, M., Berton, F., Simpson, C., Lutjens, R., Bloom, F.E., and Francesconi, W. 2002. Phosphatidylinositol 3-kinase is required for the expression but not for the induction or the maintenance of long-term potentiation in the hippocampal CA1 region. J. Neurosci. 22: 3359-3365.

Schoepfer, R., Monyer, H., Sommer, B., Wisden, W., Sprengel, R., Kuner, T., Lomeli, H., Herb, A., Kohler, M., Burnashev, N., et al. 1994. Molecular biology of glutamate receptors. Prog. Neurobiol. 42: 353-357.

Sheng, M. and Kim, M.J. 2002. Postsynaptic signaling and plasticity mechanisms. Science 298: 776-780.

Shi, S., Hayashi, Y., Esteban, J.A., and Malinow, R. 2001. Subunit-specific rules governing AMPA receptor trafficking to synapses in hippocampal pyramidal neurons. Cell 105: 331343.

Song, I. and Huganir, R.L. 2002. Regulation of AMPA receptors during synaptic plasticity. Trends Neurosci. 25: 578-588.

Steriade, M. and McCarley, R.W. 1990. Brainstem control of wakefulness and sleep. Plenum Press, New York.

Takahashi, T., Svoboda, K., and Malinow, R. 2003. Experience strengthening transmission by driving AMPA receptors into synapses. Science 299: 1585-1588.

Takasu, M.A., Dalva, M.B., Zigmond, R.E., and Greenberg, M.E. 2002. Modulation of NMDA receptor-dependent calcium influx and gene expression through EphB receptors. Science 295: 491-495.

Tang, S.J., Reis, G., Kang, H., Gingras, A.C., Sonenberg, N., and Schuman, E.M. 2002. A rapamycin-sensitive signaling pathway contributes to long-term synaptic plasticity in the hippocampus. Proc. Natl. Acad. Sci. 99: 467-472.

Tee, A.R., Manning, B.D., Roux, P.P., Cantley, L.C., and Blenis, J. 2003. Tuberous sclerosis complex gene products, Tuberin and Hamartin, control mTOR signaling by acting as a GTPase-activating protein complex toward Rheb. Curr. Biol. 13: $1259-1268$. 
Thomas, G.M. and Huganir, R.L. 2004. MAPK cascade signalling and synaptic plasticity. Nat. Rev. Neurosci. 5: 173-183.

Tian, X., Gotoh, T., Tsuji, K., Lo, E.H., Huang, S., and Feig, L.A. 2004. Developmentally regulated role for Ras-GRFs in coupling NMDA glutamate receptors to Ras, Erk and CREB. ЕМВО J. 23: 1567-1575.

Tong, J., Hannan, F., Zhu, Y., Bernards, A., and Zhong, Y. 2002. Neurofibromin regulates $G$ protein-stimulated adenylyl cyclase activity. Nat. Neurosci. 5: 95-96.

Trivier, E., De Cesare, D., Jacquot, S., Pannetier, S., Zackai, E., Young, I., Mandel, J.L., Sassone-Corsi, P., and Hanauer, A. 1996. Mutations in the kinase Rsk-2 associated with CoffinLowry syndrome. Nature 384: 567-570.

Verheijen, M.H., Wolthuis, R.M., Defize, L.H., den Hertog, J., and Bos, J.L. 1999. Interdependent action of RalGEF and Erk in Ras-induced primitive endoderm differentiation of $\mathrm{F} 9 \mathrm{em}$ bryonal carcinoma cells. Oncogene 18: 4435-4439.

Vivanco, I. and Sawyers, C.L. 2002. The phosphatidylinositol 3 -Kinase AKT pathway in human cancer. Nat. Rev. Cancer 2: 489-501.

Wennstrom, S. and Downward, J. 1999. Role of phosphoinositide 3-kinase in activation of ras and mitogen-activated protein kinase by epidermal growth factor. Mol. Cell. Biol. 19: 4279-4288.

White, M.A., Nicolette, C., Minden, A., Polverino, A., Van Aelst, L., Karin, M., and Wigler, M.H. 1995. Multiple Ras functions can contribute to mammalian cell transformation. Cell 80: $533-541$.

Winder, D.G., Martin, K.C., Muzzio, I.A., Rohrer, D., Chruscinski, A., Kobilka, B., and Kandel, E.R. 1999. ERK plays a regulatory role in induction of LTP by $\theta$ frequency stimulation and its modulation by $\beta$-adrenergic receptors. Neuron 24: 715-726.

Wolthuis, R.M., Franke, B., van Triest, M., Bauer, B., Cool, R.H., Camonis, J.H., Akkerman, J.W., and Bos, J.L. 1998. Activation of the small GTPase Ral in platelets. Mol. Cell. Biol. 18: 2486-2491.

Wu, G.Y., Deisseroth, K., and Tsien, R.W. 2001. Spaced stimuli stabilize MAPK pathway activation and its effects on dendritic morphology. Nat. Neurosci. 4: 151-158.

Yamamori, B., Kuroda, S., Shimizu, K., Fukui, K., Ohtsuka, T., and Takai, Y. 1995. Purification of a Ras-dependent mitogenactivated protein kinase kinase kinase from bovine brain cytosol and its identification as a complex of B-Raf and 143-3 proteins. J. Biol. Chem. 270: 11723-11726.

Yntema, H.G., van den Helm, B., Kissing, J., van Duijnhoven, G., Poppelaars, F., Chelly, J., Moraine, C., Fryns, J.P., Hamel, B.C., Heilbronner, H., et al. 1999. A novel ribosomal S6kinase (RSK4; RPS6KA6) is commonly deleted in patients with complex X-linked mental retardation. Genomics 62: 332-343.

Zamanillo, D., Sprengel, R., Hvalby, O., Jensen, V., Burnashev, N., Rozov, A., Kaiser, K.M., Koster, H.J., Borchardt, T., Worley, P., et al. 1999. Importance of AMPA receptors for hippocampal synaptic plasticity but not for spatial learning. Science 284: 1805-1811.

Zhang, B.H. and Guan, K.L. 2000. Activation of B-Raf kinase requires phosphorylation of the conserved residues Thr598 and Ser601. EMBO J. 19: 5429-5439.

Zhu, J.J. and Connors, B.W. 1999. Intrinsic firing patterns and whisker-evoked synaptic responses of neurons in the rat barrel cortex. J. Neurophysiol. 81: 1171-1183.

Zhu, J.J., Esteban, J.A., Hayashi, Y., and Malinow, R. 2000. Postnatal synaptic potentiation: Delivery of GluR4-containing AMPA receptors by spontaneous activity. Nat. Neurosci. 3: 1098-1106.
Zhu, J.J., Qin, Y., Zhao, M., Van Aelst, L., and Malinow, R. 2002. Ras and Rap control AMPA receptor trafficking during synaptic plasticity. Cell 110: 443-455.

Zhu, Y., Pak, D., Qin, Y., McCormack, S.G., Kim, M.J., Baumgart, J.P., Velamoor, V., Auberson, Y.P., Osten, P., van Aelst, L., et al. 2005. Rap2-JNK removes synaptic AMPA receptors during depotentiation. Neuron 46: 905-916. 


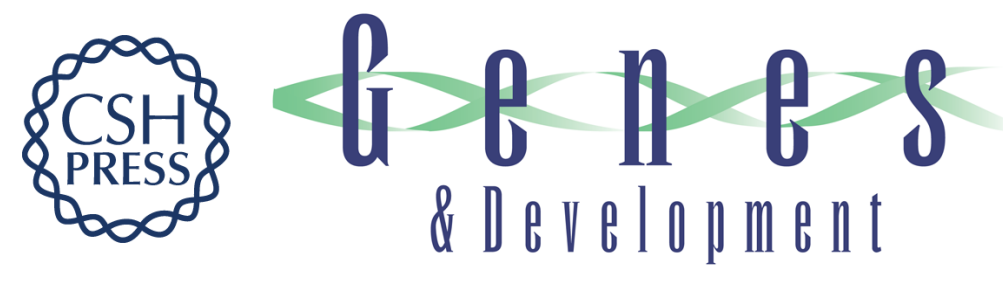

\section{State-dependent Ras signaling and AMPA receptor trafficking}

Yi Qin, Yinghua Zhu, Joel P. Baumgart, et al.

Genes Dev. 2005, 19:

Access the most recent version at doi:10.1101/gad.342205

Supplemental

Material

References

License

Email Alerting Service
http://genesdev.cshlp.org/content/suppl/2005/08/18/gad.342205.DC1

This article cites 84 articles, 33 of which can be accessed free at: http://genesdev.cshlp.org/content/19/17/2000.full.html\#ref-list-1

Receive free email alerts when new articles cite this article - sign up in the box at the top right corner of the article or click here.

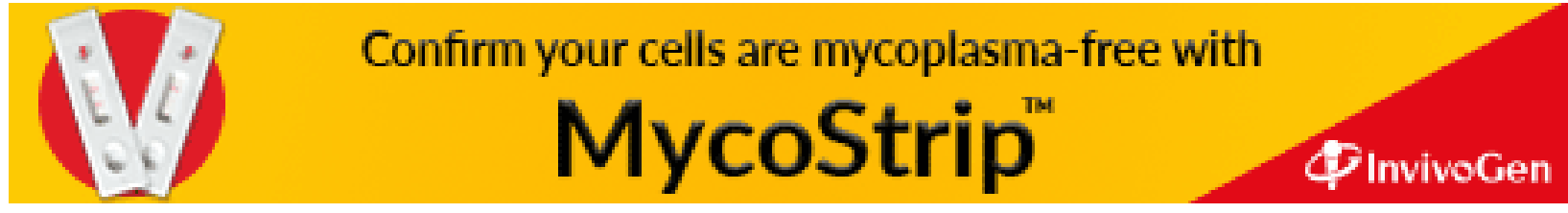

